UNIVERSIDADE DE SÃo PAULO

FACUldADE DE MEDICINA DE RIBEIRÃo PRETO

DEPARTAMENTO DE GENÉTICA

\title{
Análise da influência do hormônio anti-Mülleriano na produção in vitro de embriões bovinos
}

Adriana Renzi

Ribeirão Preto - SP 


\section{Adriana Renzi}

\section{Análise da influência do hormônio anti-Mülleriano na produção in vitro de embriões bovinos}

Tese de Doutorado apresentada ao Departamento de Genética da Faculdade de Medicina de Ribeirão Preto como pré-requisito para a obtenção do título de Doutor em Ciências Biológicas.

Área de Concentração: Genética.

Orientador: Prof. Dr. Raysildo Barbosa Lôbo

Ribeirão Preto - SP 
AUTORIZO A DIVULGAÇÃO TOTAL OU PARCIAL DESTE TRABALHO, POR QUALQUER MEIO CONVENCIONAL OU ELETRÔNICO, PARA FINS DE ESTUDO E PESQUISA, DESDE QUE CITADA A FONTE.

FICHA CATALOGRÁFICA

Renzi, Adriana

Análise da influência do hormônio anti-Müleriano na produção in vitro de embriões bovinos, 2012.

67p: il.; $30 \mathrm{~cm}$

Tese de Doutorado, apresentada à Faculdade de Medicina de Ribeirão Preto/USP - Área de concentração: Genética.

Orientador: Lôbo, Raysildo B. 


\section{FOLHA DE APROVAÇÃO}

Adriana Renzi

ANÁLISE DA INFLUÊNCIA DO HORMÔNIO ANTI-MÜLLERIANO NA PRODUÇÃO IN VITRO DE EMBRIÕES BOVNOS, 2012.

Tese apresentada à Faculdade de Medicina de Ribeirão Preto da Universidade de São Paulo para obtenção do título de Doutor em Ciências. Área de Concentração: Genética

\section{BANCA EXAMINADORA}

Data da Defesa:

Prof. Dr. Raysildo Barbosa Lôbo

Julgamento:

Assinatura:

Prof. Dr.

Julgamento: Assinatura:

Prof. Dr.

Julgamento:

Assinatura:

Prof. Dr.

Julgamento:

Assinatura:

Prof. Dr.

Julgamento: Assinatura: 
Este trabalho foi desenvolvido com o apoio financeiro da Coordenação de Aperfeiçoamento de Pessoal de Nível Superior (CAPES), da Fundação de Amparo ao Ensino Pesquisa e assistência do Hospital das Clínicas da Faculdade de Medicina de Ribeirão Preto (FAEPA), do Conselho Nacional de Desenvolvimento de Pesquisa $(\mathrm{CNPq})$ e da Fundação de Apoio à Pesquisa do Estado de São Paulo (FAPESP) 
Aos meus pais Irineu e Marilda pelo amor incondicional e incentivo constante, que não me deixaram desistir.

Minha eterna gratidão!

Aos meus irmãos, Pelo apoio e amizade.

À todos meus amigos. Muito obrigada!!! 


\section{AGRADECIMENTOS}

A Deus, pela minha existência, minha família, minha saúde e por me iluminar e dar forças na minha vida.

Aos meus amados pais, Irineu Renzi e Marilda Moreira Renzi por tudo que me proporcionaram até o dia de hoje, por todo amor, paciência e apoio incondicional para a conquista de meus sonhos, participando de todos os momentos da minha vida.

Aos meus queridos irmãos, Irineu Renzi Junior e Daniela Renzi, pelo carinho, apoio, companheirismo, paciência e ajuda nas horas em que eu mais precisei.

Ao meu orientador Prof. Dr. Raysildo Barbosa Lôbo, pelo aprendizado, dedicação e pela oportunidade da realização deste trabalho em seu laboratório.

Aos membros da banca examinadora que dedicaram parte do seu tempo para a avaliação deste trabalho.

Ao Conselho Nacional de Pesquisa pela bolsa de doutorado e incentivo a pesquisa.

À Fernanda Prado Elias principalmente pela amizade, mas também por todo ensinamento, pela paciência e por estar sempre disponível para me ajudar.

Ao técnico e amigo Reginaldo Aparecido Vila pela amizade, ensinamentos e ajuda, que tornaram possível a realização deste trabalho

Aos meus queridos amigos do Laboratório: Anderson Mioranza, Rafaella C. Lemes e Vivian T. F. Cipriano, pela ajuda valiosa, paciência, e principalmente pela amizade e companheirismo.

Aos técnicos e amigos Marli Aparecida Vanni Galerani, Sílvio Avelino dos Santos, Luiz Antônio Framartino Bezerra e Sebastião Pauo Framartino Bezerra, pela amizade, ajuda e agradável convivência.

À Prof. Dra. Ester Silveira Ramos, Profa. Dra. Lúcia Regina Martelli e Prof.Dr. Rui Alberto Ferriani pela disponibilização de seus laboratórios, contribuindo muito com o andamento deste trabalho, além dos incentivos e amizade. 
Aos amigos do laboratório do Bloco C: Alexandra Galvão, Ciro Pereira, Cristiana L. M. Furtado, Filipe Brum, Flávia Gaona, Karine Salomão, Hélida Magalhães, Larissa O. Guimarães, Murilo R. Soares, e Sarah Blima pela amizade e por se mostrarem sempre prontos a ajudar no que for preciso.

À Tânia Paula Aquino Defina por toda a ajuda que me concedeu, tanto na parte profissional, como também na pessoal. Muito obrigada por todo o auxílio nas tarefas do laboratório e pela amizade, cumplicidade, apoio e carinho.

Às meninas do Laboratório de Reprodução, Cristiana C. P. Ribas, Juliana Meola e Lilian E. C. M da Silva pela ajuda imprescindível, e pela amizade. Sem vocês este trabalho não sairia.

Às secretárias do Departamento de Genética da FMRP - USP, Susie, Maria e Sílvia, pelo carinho e auxílio.

Ao Fausto Bruno dos Reis Almeida pelo socorro de última hora. Sua ajuda e amizade foram fundamentais.

Ao Wellington de Paula Martins e Henrique Nunes de Oliveira, pela ajuda nas análises estatísticas.

Agradecimento especial em nome da amizade conquistada à Nerry Tatiana Cecílio por em tão pouco tempo ter se tornado uma amiga tão presente em minha vida, por ser uma pessoa tão especial e importante para mim em toda essa caminhada. Não sei o que faria sem sua ajuda.

À minha querida amiga Mara pelo cafezinho de todas as horas e pela amizade e momentos de descontração.

Aos todos os meus queridos amigos externos ao laboratório que colaboraram, de alguma forma, para meu crescimento, e que são essenciais à minha vida!!!! Obrigada por vocês existirem!!!!

Aos professores, alunos e funcionários do Departamento de Genética da FMRP.

A todos aqueles os quais não mencionei, mas que estão ou já passaram em minha vida e que me ajudam ou ajudaram na minha formação como um ser humano. 
"Se eu soubesse o que eu estava fazendo, não seria chamada pesquisa."

(Albert Einstein) 


\section{RESUMO}

Renzi, A. Análise da influência do hormônio anti-Mülleriano na produção in vitro de embriões bovinos. 2012. Tese (Doutorado). Faculdade de Medicina de Ribeirão Preto Universidade de São Paulo, Ribeirão Preto, 2012.

A maturação in vitro de oócitos (MIV) é uma importante tecnologia reprodutiva a qual gera oócitos maduros capazes de suportar o desenvolvimento embrionário pré-implantacional e sua completa evolução à termo. Muitos fatores levam ao processo de maturação do oócito, e o AMH (hormônio anti-Mülleriano) tem demonstrado possuir um importante efeito nesta etapa. Neste trabalho nós demonstramos a influência da suplementação de AMH na maturação de complexos cumulus-oócito (COCs). Nossos resultados demonstram que não houve efeito na produção de embriões para COCS grau I. Entretanto, pudemos encontrar diferenças significativas entre os COCs graus II e III maturados na presença de 150ng/ml de AMH. Aqui também demonstramos que não houve diferença significativa na expressão relativa de mRNA para os genes AMHRII e FSHR no oócito, e na expressão relativa de mRNA para os genes AMH, AMHRII e FSHR nas células da granulosa. Nossos resultados corroboram com as importantes funções do $\mathrm{AMH}$ na produção de embriões, sugerem que a suplementação do meio de maturação de oócitos com AMH pode ajudar a melhorar a produção de blastocistos. 


\begin{abstract}
Renzi, A. Analysis Influence of the anti-Müllerian hormone on in vitro bovine embryo production 2012. Tese (Doutorado). Faculdade de Medicina de Ribeirão Preto - Universidade de São Paulo, Ribeirão Preto, 2012.

The in vitro oocyte maturation (MIV) is an important reproductive technology that generates mature oocytes able to support the preimplantation embryonic development and their fully evolution to term. Many factors lead to oocyte maturation process, and the AMH (AntiMüllerian hormone) have demonstrated important effects in the oocyte development. Here, we report the influence of AMH supplementation in the cumulus-oocyte complex (COCs) maturation. We found that AMH had no effect on embryo production of COCs grade I. On the other hand, significant differences between the COCs grade II and COCs grade III matured in $\mathrm{AMH} 150 \mathrm{ng} / \mathrm{ml}$ were verified. We have also demonstrated that there were no significant difference in mRNA expression of the genes AMHRII and FSHR in the oocyte, and in mRNA of the genes AMH, AMHRII and FSHR in the granulosa cells. Taken together, the results corroborate the important roles for $\mathrm{AMH}$ on embryo production, and suggest that $\mathrm{AMH}$ supplementation could achieve successful outcome in the production of blastocysts.
\end{abstract}




\section{LISTA DE FIGURAS}

Figura 1. Representação esquemática do crescimento, capacitação e maturação de um oócito bovino através da foliculogênese.

Figura 2. Representação esquemática de um folículo antral com suas estruturas observadas.

Figura 3. Classificação dos COCs em graus I, II e III de acordo com sua morfologia 31

Figura 4. Complexo cumulus-oócitos grau 1 após $24 \mathrm{~h}$ de maturação in vitro 32

Figura 5. Interação entre espermatozóides e oócitos após 12 horas. 34

Figura 6. Embriões viáveis ao sétimo dia de desenvolvimento após fertilização in vitro. 35

Figura 7. Porcentagem de embriões desenvolvidos ao sétimo dia de cultivo in vitro (número de embriões/número e oócitos) para COCs grau II e III, maturados nas diferentes concentrações de AMH.

Figura 8. Expressão relativa de mRNA (unidades arbitrárias) de $\operatorname{AMHRII}(A, p=0.12)$ e FSHR (B, p=0.27) nos oócitos provenientes de COCs graus I, II e III, após maturação em diferentes concentrações de $\mathrm{AMH}(0,10,50,150$ e $300 \mathrm{ng} / \mathrm{ml})$.

Figura 9. Expressão relativa de mRNA (unidades arbitrárias) de $\mathrm{AMH}(\mathrm{A}, \mathrm{p}=0.99)$, AMHRII ( $\mathrm{B}, \mathrm{p}=0.49)$ e FSHR $(\mathrm{C}, \mathrm{p}=0.50)$ nas células da granulosa provenientes de COCs graus I, II e III, após maturação em diferentes concentrações de AMH (0, 10, 50, 150 e $300 \mathrm{ng} / \mathrm{ml})$. 


\section{LISTA DE TABELAS}

Tabela 1. Ensaios TaqMan ${ }^{\circledR}$ de expressão gênica para PCR em tempo real utilizados neste trabalho. AMH e GAPDH - Assay-on-Demand ${ }^{\mathrm{TM}}$ Gene Expression Products e AMHRII e FSHR - Custom TaqMan ${ }^{\circledR}$ Assays.

Tabela 2. Produção de embriões in vitro utilizando oócitos provenientes de COCs grau I, em diferentes concentrações de AMH.

Tabela 3. Produção de embriões in vitro utilizando oócitos provenientes de COCs grau II, em diferentes concentrações de AMH.

Tabela 4. Produção de embriões in vitro utilizando oócitos provenientes de COCs grau III, em diferentes concentrações de AMH 


\section{LISTA DE ABREVIATURAS}

AMH - hormônio anti-Mülleriano

AMHRII - receptor do AMH tipo II

bFGF - $\quad$ Fator de crescimento de fibroblástico básico

Be - $\quad$ Blastocisto eclodido

Bi - $\quad$ Blastocisto inicial

B1 - $\quad$ Blastocisto

Bx - $\quad$ Blastocisto expandido

CIV - $\quad$ Cultivo in vitro

cDNA - DNA complementar

COCs - Complexos cumulus-oócito

FIV - $\quad$ Fertilização in vitro

FMRP - $\quad$ Faculdade de Medicina de Ribeirão Preto

FSH - $\quad$ Hormônio Folículo Estimulante

FSHR - Receptor do hormônio Folículo Estimulante

GAPDH - glyceraldehyde-3-phosphate dehydrogenase

GDF-9 - $\quad$ Fator de crescimento de diferenciação 9

IA - $\quad$ Inseminação Artificial

LH - Hormônio Luteinizante

LMEM - Laboratório de Micromanipulação de Embriões e Molecular

MIV - $\quad$ Maturação in vitro

mRNA - $\quad$ RNA mensageiro

NGF - $\quad$ Fator de crescimento neuronal

OPU - $\quad$ do inglês Ovum Pick Up (Punção Folicular)

PIV - $\quad$ Produção in vitro

TE - $\quad$ Transferência de embriões

TGF- $\beta$ - $\quad$ Fatores de Crescimento Transformantes $\beta$

SCF - $\quad$ Fator de célula tronco

VG - Vesícula germinativa 


\section{SUMÁRIO}

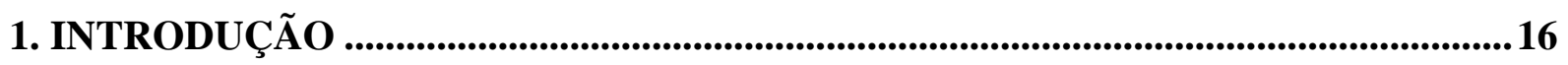

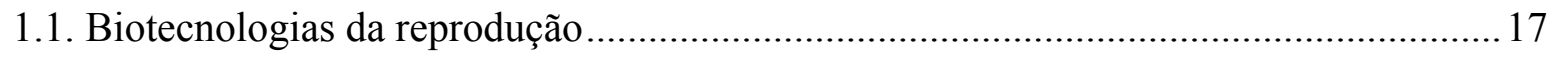

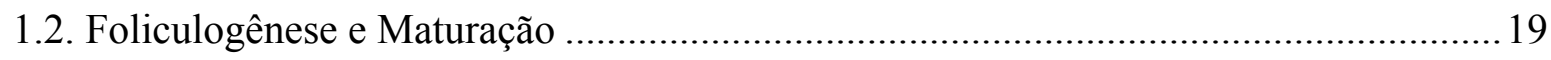

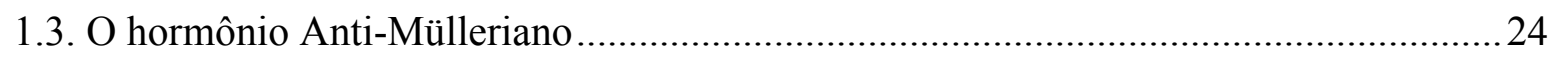

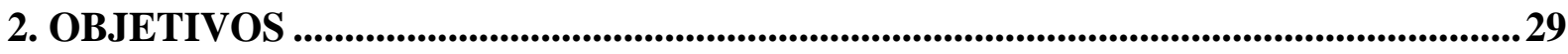

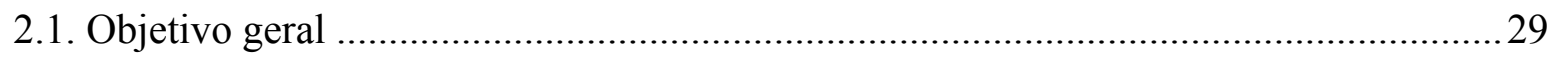

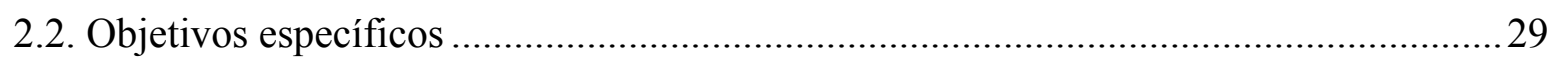

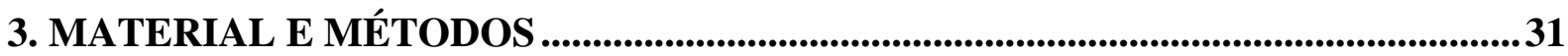

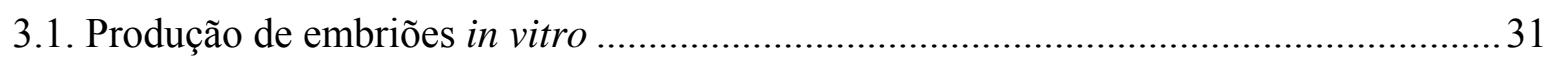

3.1.1. Coleta de oócitos e Maturação in vitro .................................................................. 31

3.1.2. Seleção de espermatozóides e ajuste da concentração espermática......................... 33

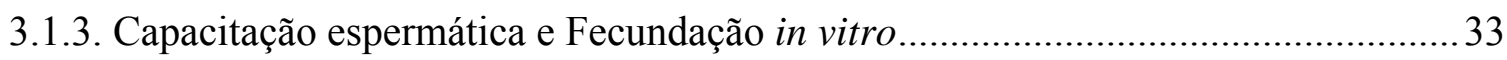

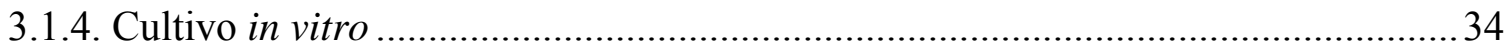

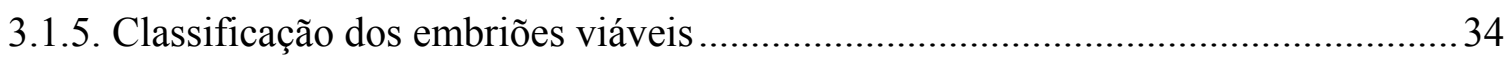

3.2. Análise quantitativa de expressão gênica por meio da reação em cadeia da polimerase em tempo real em COCs maturados na presença ou ausência do AMH ............ 36

3.2.1. Coleta de oócitos e maturação in vitro ................................................................... 36

3.2.2. Remoção das células do cumulus dos COCs........................................................... 36

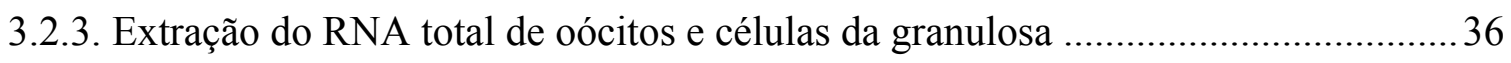

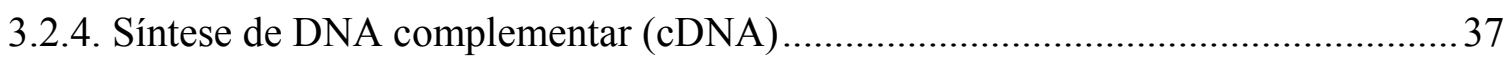

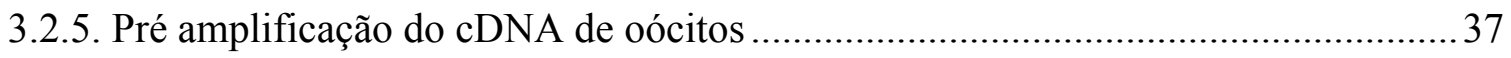

3.2.6. Estudo da expressão gênica por PCR em Tempo Real ........................................... 38

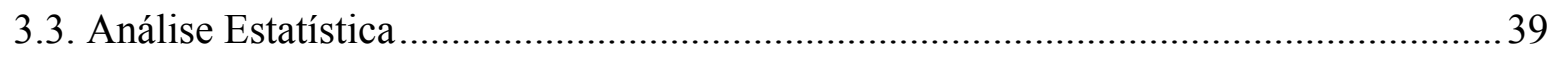

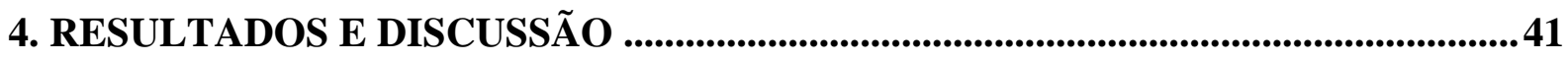

4.1. A adição do hormônio anti-Mülleriano ao meio de maturação influencia na produção in vitro de embriões bovinos ........................................................................... 41

4.2. A expressão relativa de mRNA dos genes AMHRII e FSHR em oócitos e dos genes AMH, AMHRII e FSHR em células da granulosa não sofre influência do hormônio antiMülleriano quando adicionado ao meio de maturação de COCs de diferentes qualidades

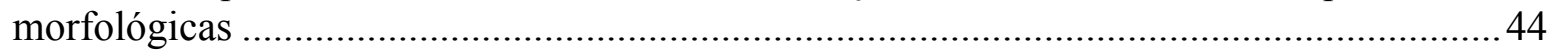

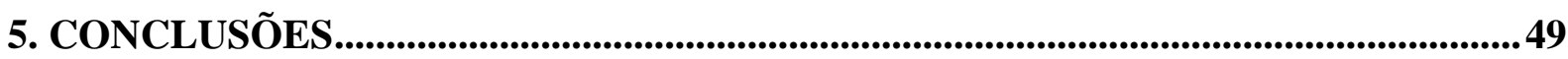

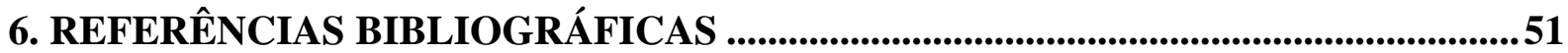

ANEXO DE PUBLICAÇÃO 


\section{INTRODUÇÃO}

O conhecimento a respeito da embriologia dos mamíferos vem progredindo muito nos últimos 30 anos com o desenvolvimento de uma ampla tecnologia com aplicações clínicas, farmacêuticas e de pesquisa. Após o nascimento de Louise Brown em 1978, na Inglaterra (Steptoe e Edwards, 1978), a produção in vitro de embriões expandiu-se nas diferentes espécies animais. Em nível mundial, a evolução tecnológica no domínio da reprodução tem crescido a uma velocidade vertiginosa, sendo a manipulação reprodutiva uma ferramenta indispensável para o avanço científico em vários domínios (Borba, 2008).

No que diz respeito à produtividade na pecuária bovina, pode-se dizer que os avanços na área de reprodução têm contribuído de forma decisiva, possibilitando a exploração efetiva de animais de valor genético superior, além de ter se tornado imprescindível na preservação de material genético raro ou em risco de extinção. Esses progressos têm sido de extrema importância para a pesquisa em reprodução animal, proporcionando modelos experimentais para o estudo do desenvolvimento folicular, ovulação, fertilização, reconhecimento da gestação e sobrevivência embrionária (Betteridge, 2003). Entretanto parece óbvio que ainda precisamos aprender muito sobre a fisiologia dos gametas e embriões, uma vez que a taxa de sucesso da maioria das tecnologias in vitro ainda está abaixo do que nós consideramos normal in vivo (Krisher and Wheeler, 2010). Segundo Gonçalves e colaboradores (2008), os índices de blastocistos produzidos in vitro para bovinos variam em torno de $20-50 \%$, sendo que os embriões que conseguem se desenvolver in vitro apresentam qualidade inferior àqueles produzidos in vivo, segundo parâmetros como morfologia, criotolerância, transcrição, eclosão in vitro e prenhez após a transferência. Sendo assim, podemos dizer que o aumento da eficiência desta técnica está condicionado ao desenvolvimento de trabalhos que visem aperfeiçoar e simplificar as condições de cultivo durante as várias etapas do processo, principalmente no que se refere à maturação citoplasmática e molecular de oócitos obtidos in vitro (Gonçalves et al., 2008).

A maturação in vitro (MIV) é uma importante tecnologia, já que tem o potencial de capturar o vasto estoque de oócitos dentro de um ovário. Nos animais domésticos, a produção de embriões a partir de ovários não estimulados utilizando a MIV é uma prática rotineira, sendo importante plataforma tecnológica para a reprodução artificial, clonagem e produção de animais transgênicos. Já em humanos, o tratamento da infertilidade com a MIV não tem tanto sucesso e esta técnica é pouco utilizada. Existe porém grande interesse no seu 
desenvolvimento, que levaria a um menor uso de hormônios estimulantes e seus efeitos colaterais, além da diminuição dos custos do procedimento (Gilchrist and Thompson, 2007).

Apesar de ser uma prática muito utilizada, a MIV não é um processo natural, diferindo da maturação in vivo em dois aspectos fundamentais: os complexos cumulus-oócito (COCs cumulus-oocyte complex) são normalmente coletados de folículos antrais de tamanho médio e que ainda não completaram o processo de capacitação oocitária, logo não possuem a maquinaria molecular e celular necessária para manter o início da embriogênese; e a ação mecânica de remover os COCs do folículo resulta na perda do ambiente natural inibitório da meiose, levando à maturação meiótica oocitária "espontânea" in vitro. A eficiência das tecnologias de MIV dos oócitos está limitada pelo desenvolvimento da competência intrínseca, que se refere ao estado bioquímico e molecular que permite o oócito maduro ser fertilizado normalmente e se desenvolver em um embrião, o qual, na transferência, irá permitir o desenvolvimento a termo (Gilchrist and Thompson, 2007). Apesar das suas limitações, esta é uma tecnologia muito valiosa uma vez que permite lidar com uma população de oócitos muito diferente, coletados de folículos em vários estágios do desenvolvimento, dominância e atresia (Gilchrist and Thompson, 2007).

Dentre os fatores que afetam o desenvolvimento do oócito, têm recebido atenção os efeitos do hormônio Anti-Mülleriano (AMH). Além do papel inibidor do AMH no recrutamento de folículos primordiais pelos folículos vizinhos em crescimento que o secretam (Durlinger et al. 1999), sua função também pode estar correlacionada com o desenvolvimento de oócitos e sua fertilização (Takahashi et al. 2008) e manutenção da dominância folicular após a seleção do mesmo (Hayashi et al. 2010).

\subsection{Biotecnologias da reprodução}

A biotecnologia da reprodução se tornou um dos negócios de grande destaque em todo mundo, se tornando uma ferramenta poderosa para os criadores de animais e cientistas, no que diz respeito ao melhoramento genético de rebanhos animais. Nos últimos 40 anos, estudos tanto nas áreas básicas (superovulação, recuperação não cirúrgica de oócitos e transferência de embriões bovinos), como aplicadas (produção in vitro de embriões, transferência nuclear, transgenia) têm gerado uma vasta literatura sobre fatores reguladores do desenvolvimento e qualidade dos oócitos e embriões. Esta tecnologia evoluiu através de três grandes mudanças: transferência embrionária tradicional (produção de embriões in vivo através da superovulação de doadoras), produção de embriões in vitro através da coleta de oócitos por punção folicular 
guiada por ultra-som (OPU - ovum pick up) com fertilização in vitro (FIV), e clonagem, através de transferência nuclear de células somáticas e produção de animais transgênicos $(\mathrm{Wu}$ and Zan, 2011). Atualmente, algumas dessas técnicas já apresentam grande aplicabilidade a campo como a inseminação artificial, a sexagem de sêmen, a transferência e criopreservação de embriões e a produção in vitro de embriões, enquanto outras ainda permanecem mais restritas a centros de pesquisa, como a transgenia e a clonagem.

Toda esta tecnologia disponível atualmente tem permitido avanços significativos, tais como: indução e controle da atividade reprodutiva; produtividade em períodos não tradicionais em algumas espécies de reprodução sazonal; maximização e aceleração do progresso genético em espécies de importância econômica; preservação de espécies em extinção, controle de doenças; e aprimoramento ou criação de novos produtos ou fármacos, através de animais transgênicos (Deschamps et al. 2000).

De todas as biotécnicas utilizadas em reprodução animal, a inseminação artificial (IA) é a mais antiga, mais simples e de maior impacto na produção animal, sendo difundida em todo o mundo como um instrumento eficaz e econômico para ser utilizado no melhoramento genético. A transferência de embriões (TE) continua sendo um dos métodos mais econômicos e práticos para o aumento das taxas reprodutivas de fêmeas de alto valor genético tanto em rebanho de leite como de corte (Neves et al. 2010). Sua importância básica para a reprodução animal se deve ao fato de que uma fêmea pode produzir um número de descendentes muito maior em relação a quantidade que poderia obter fisiologicamente por toda sua vida reprodutiva, através do processo de superovulação (induzido quimicamente), fertilização e transferência desses embriões para um animal receptor. O desenvolvimento das técnicas de criopreservação de embriões foi fundamental para esta técnica, uma vez que possibilita o transporte dos embriões congelados entre rebanhos, evitando custos e dificuldades do deslocamento de animais.

A produção in vitro de embriões (PIV) é também uma biotécnica de reprodução assistida e uma ferramenta de pesquisa de eventos relacionados à maturação e fecundação de oócitos, capacitação espermática e desenvolvimento embrionário na fase de pré-implantação. Além disso, atua como instrumento de suporte para outras biotécnicas como clonagem, trangenese e transferência nuclear (Gonçalvez et al., 2008). Aliada à técnica de transferência de embriões, esta tecnologia torna possível aumentar a vida reprodutiva de animais de alto valor genético dos quais possam ser utilizados oócitos normais (fêmeas que não respondem aos tratamentos de superovulação, fêmeas imaturas, fêmeas idosas, ou aquelas que apresentem infertilidade adquirida devido à patologias no trato reprodutivo, impossibilitando 
sua fertilização e o desenvolvimento embrionário in vivo). Essa técnica vem sendo gradativamente incorporada nos programas de melhoramento animal como técnica de multiplicação, sendo que seu uso tem aumentado significativamente no país. De fato, o Brasil hoje ocupa uma posição de destaque no cenário mundial com consequente reconhecimento internacional, sendo responsável por quase $50 \%$ da produção mundial de embriões in vitro (Neves et al. 2010).

A PIV envolve três etapas: a maturação oocitária in vitro (MIV), seguida pela fertilização dos oócitos in vitro (FIV), sendo finalizada pelo cultivo in vitro (CIV) dos embriões até os estádios de blastocisto. Mesmo com todo conhecimento sobre essa técnica, as regulações bioquímicas e hormonais envolvidas na produção final de embriões não são completamente conhecidas, havendo a necessidade de comprovação ou elucidação de muitos mecanismos envolvidos no processo fisiológico como um todo. Entretanto, os estudos in vitro têm sido de imensurável valia no esclarecimento de regulações na maturação dos gametas femininos, fertilização e desenvolvimento embrionário precoce, os quais têm contribuído de modo significativo para a pesquisa, a produção animal e a qualidade de vida do homem em vários aspectos, pela importância tanto na reprodução humana e animal, quanto facilitando a implementação e o desenvolvimento de outras biotecnologias (Gonçalves et al. 2008).

\subsection{Foliculogênese e Maturação}

Estudos abordando a maturação in vitro (MIV) têm sido realizados desde 1955, quando Chang (1955) conseguiu realizar o nascimento de um coelho utilizando oócitos maturados in vitro. Na década de 60, Edwards (1965) verificou que o desenvolvimento da maturação nuclear dos oócitos, a partir da remoção dos mesmos do ambiente folicular, era um fenômeno comum em várias espécies, incluindo a bovina. Ao cultivar in vitro oócitos inclusos em folículos e oócitos livres, foi possível concluir que o fator inibitório da maturação estava presente no folículo, pois este desaparecia com a remoção dos oócitos do ambiente folicular, causando a retomada da meiose (Edwards, 1962, 1965, 1966 citado por Varago et al. 2008).

A MIV é uma importante tecnologia reprodutiva, que gera oócitos maduros capazes de manter o desenvolvimento embrionário pré-implantacional e o completo desenvolvimento a termo. Hoje em dia existe um grande incentivo, tanto clínico, como comercial para melhorar a eficiência desta tecnologia, entretanto, o progresso tem sido lento nos últimos anos (Gilchrist and Thompson, 2007). O processo de maturação inclui todos os eventos que permitem ao oócito expressar seu potencial máximo de desenvolvimento após a fecundação. Assim, 
podemos dizer que é uma das fases mais importantes da PIV de embriões, pois é nesse período que o oócito adquire capacidade para prosseguir nos próximos eventos (FIV e CIV) (Gottardi e Mingoti, 2009).

O processo de formação dos oócitos (oogênese) se inicia na vida fetal, quando as células germinativas, após sucessivas mitoses, migram pra crista gonadal, onde se diferenciam em oogônias. Após atingirem as gônadas, as células germinativas continuam a proliferar, atingindo um número máximo estimado em 2.1 milhões nos bovinos (Smitz and Cortvrindt, 2002). Nos ruminantes é sabido que a fase terminal de proliferação das oogônias e sua entrada no ciclo meiótico coexistem durante a fase terminal proliferativa. Quando entram no ciclo de divisão meiótica, os oócitos param a progressão na fase terminal da prófase I (estágio de diplóteno) por volta do nascimento, onde o núcleo é envolto por envelope nuclear ou vesícula germinativa (VG), o que caracteriza morfologicamente um oócito imaturo. Eles permanecem neste estágio durante todo o processo de crescimento dentro do folículo ovariano. $\mathrm{O}$ crescimento oocitário ocorre simultaneamente ao desenvolvimento folicular ou foliculogênese (processo de formação, crescimento e maturação dos folículos ovarianos), tendo início com a formação do folículo primordial e culminando com o estágio de folículo pré-ovulatório (van den Hurk and Zhao, 2005). Os folículos ovarianos são classificados de acordo com o grau de evolução em pré-antrais, compreendendo os primordiais, primários e secundários, e em antrais, caracterizados pela presença de uma cavidade preenchida por fluido folicular, passando a ser classificados como terciários e pré-ovulatórios. O folículo primordial é constituído por um oócito imaturo, circundado por uma simples camada de células da prégranulosa de formato pavimentoso. Quando o oócito é circundado por uma camada completa de células da granulosa de formato cúbico, o folículo é classificado como primário. A multiplicação das células da granulosa dos folículos primários leva à formação de várias camadas dessas células ao redor do oócito, formando o folículo secundário. Com a intensa proliferação das células da granulosa, uma área preenchida por fluido folicular é identificada na camada granulosa e, a partir de então, os folículos passam ser classificados como antrais. A partir desse estágio, o diâmetro folicular aumenta acentuadamente, devido ao crescimento do oócito, multiplicação das células da granulosa, da teca e aumento da cavidade antral. No último estágio do desenvolvimento folicular, o folículo pré-ovulatório é caracterizado por um oócito circundado por células da granulosa especializadas que são denominadas células do cumulus (Parrot and Skinner, 2000) (Figura 1). 


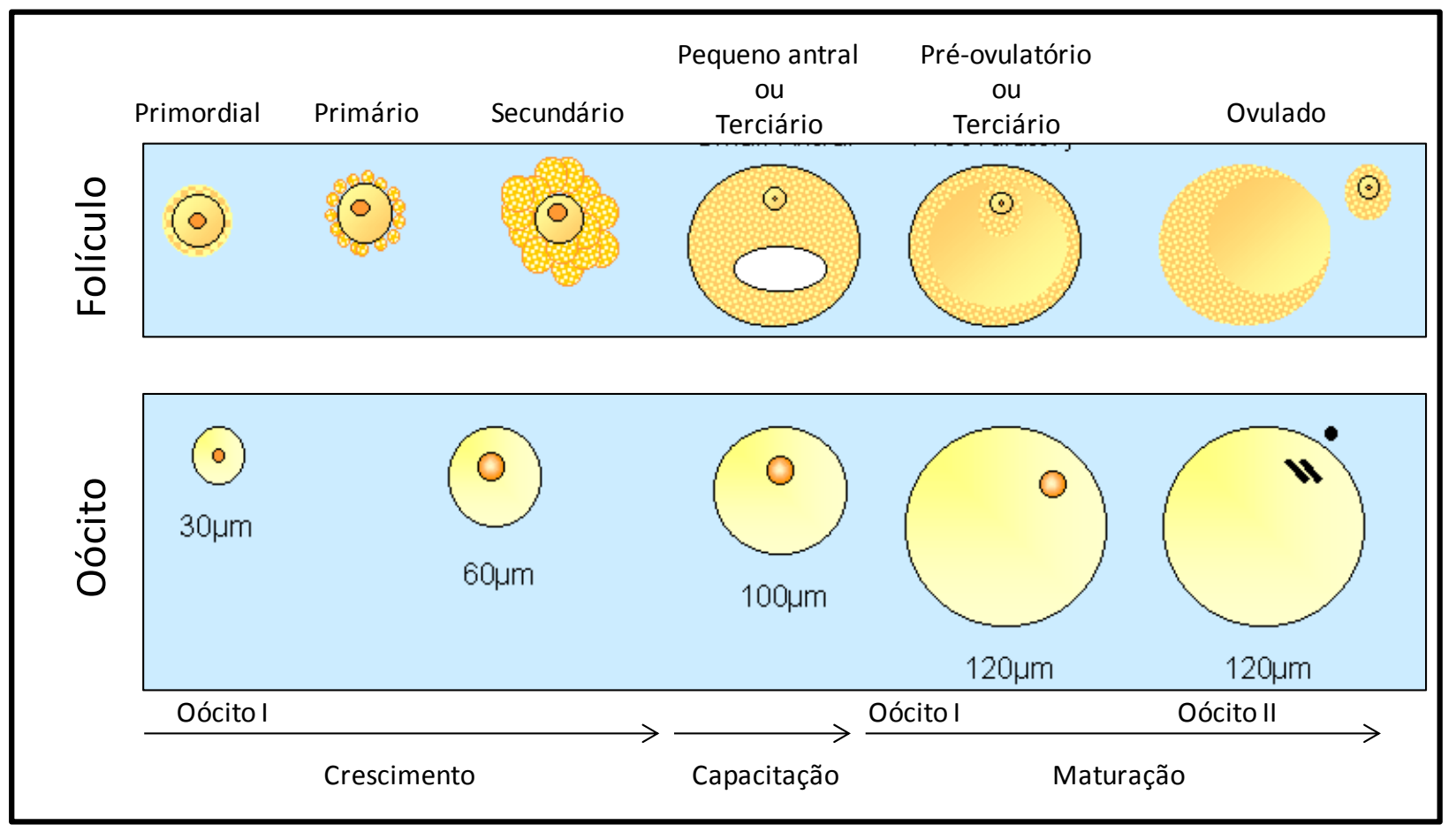

Figura 1. Representação esquemática do crescimento, capacitação e maturação de um oócito bovino através da foliculogênese. $O$ crescimento do oócito começa no início do crescimento folicular e está quase completo quando ocorre a formação do antro. $\mathrm{O}$ oócito passa por modificações os quais o permitem desenvolver sua competência. A maturação do oócito tem início após um pico do hormônio luteinizante (LH) in vivo ou após sua remoção do ambiente folicular, permitindo o oócito atingir o estágio de metáfase II e expressar sua competência após a fertilização. Adaptado de Mermillod e colaboradores (1998).

Durante a foliculogênese, dois processos de seleção regulatória, que envolvem o recrutamento de folículos, podem ser reconhecidos. Durante a primeira seleção, conhecida como recrutamento inicial, os folículos são recrutados de um pool de folículos primordiais dormentes. Durante a segunda seleção, conhecida como recrutamento cíclico, folículos em crescimento são selecionados para crescerem até o estágio pré-ovulatório. Esta seleção é resultado do aumento nos níveis de FSH (hormônio folículo estimulante) durante cada ciclo reprodutivo, e somente os grandes folículos pré-antrais e pequenos folículo antrais que são sensíveis suficientemente ao FSH, serão resgatados da atresia (McGee and Hsueh, 2000). O folículo dominante continua a crescer pela dependência transiente de FSH e LH, e secreta grande quantidade de estradiol e os folículos subordinados restantes param de crescer e sofrem atresia.

Os ovários dos mamíferos contêm um grande estoque de oócitos inclusos em folículos primordiais e a atividade cíclica do ovário induz alguns desses folículos a iniciar o crescimento em direção a uma possível ovulação. Entretanto, a maioria desses folículos sofre 
atresia durante as diferentes fases de crescimento (Mermillod et al. 2008). A função do folículo consiste em proporcionar um ambiente ideal para a manutenção da viabilidade, bem como o crescimento e a maturação do oócito. Durante a maturação, o oócito está envolto por células da granulosa, formando o complexo cumulus-oócito (COCs). O conjunto de células próximo à zona pelúcida, em íntimo contato com o oócito por junções intercomunicantes, é denominado corona radiata. Essas células do cumulus têm função diferenciada daquelas presentes no mural do folículo em consequência do seu intimo contato com o oócito (figura 2), onde substâncias reguladoras produzidas pelo oócito têm função importante nas atividade das células do cumulus e, da mesma maneira, componentes dessas células somáticas têm participação ativa no crescimento e maturação dos oócitos (Gonçalves et al. 2008). Através das junções do tipo gap, ocorre transferência de elementos para o oócito e vice-versa, existindo, portanto, uma comunicação bidirecional entre as células do cumulus e o oócito (Dode, 2006). A fase final da maturação citoplasmática e meiótica do oócito, que coincide com o desenvolvimento e crescimento dos folículos antrais, é objeto de complexas interações dos controles endócrinos, parácrinos e autócrinos. A concentração intrafolicular de alguns desses agentes em períodos específicos do desenvolvimento folicular antral parece estar relacionado com o sucesso ou não de vários processos do desenvolvimento no oócito que são essências para a fertilização e futuro desenvolvimento da competência (Fanchin et al. 2007).

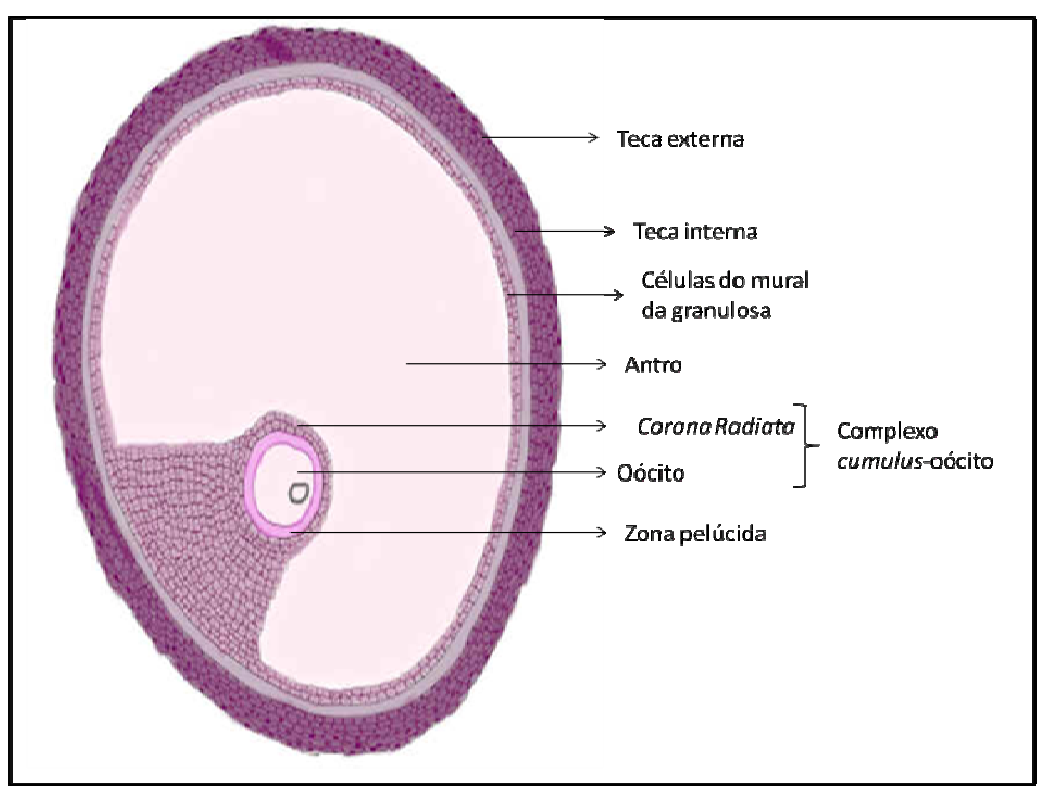

Figura 2. Representação esquemática de um folículo antral com suas estruturas observadas. (Figura adaptada de http://instruction.cvhs.okstate.edu/histology/fr/HiFRp09.htm, em 12.01.2012). 
Durante a foliculogênese, o oócito cresce, sofre modificações na sua estrutura e armazena RNA e proteínas necessárias para finalmente se tornar competente para retomar e concluir a maturação, favorecer a fertilização iniciar o remodelamento da cromatina e desenvolvimento embrionário (Mermillod et al. 2008). Para realizar todas essas tarefas com sucesso, o oócito deve passar por três etapas na maturação: meiótica, citoplasmática e molecular. Conforme o folículo cresce até o tamanho ovulatório, a atividade de síntese é gradualmente reduzida até que este atinja um estágio quiescente. Esta última fase do desenvolvimento do oócito é denominada "capacitação oocitária" (Hytell et al. 1997). No estágio de competência oocitária, nem todos os oócitos são capazes de serem fertilizados e iniciar o desenvolvimento embrionário. A proporção de competência dos oócitos aumenta durante a foliculogênese, mas após esse período, poucos oócitos alcançam o estágio final de competência devido a perda da maioria dos folículos por atresia que pode ocorrer em qualquer etapa do seu desenvolvimento. Assim, a progressão da proporção de oócitos competentes dentro de uma população de folículos em crescimento pode ser o resultado da diferenciação do oócito através do acúmulo de fatores (mensageiros, proteínas) que estarão envolvidos no sucesso do início do desenvolvimento ou o resultado da seleção de folículos contendo os oócitos mais apropriados, em um ambiente hormonal altamente seletivo e regulação intrafolicular desafiadora (Mermillod et al. 2008).

In vivo, a maturação nuclear do oócito tem inicio após um pico pré-ovulatório de hormônio luteinizante ( $\mathrm{LH})$ durante o estro e in vitro, a retirada do oócito de seu ambiente folicular reinicia a meiose (Edwards, 1965). As alterações nas condições de maturação podem afetar a competência do oócito significantemente, o que pode ser verificado pela produção de mórulas e blastocistos após a FIV. A maturação in vivo difere da MIV em dois aspectos fundamentais: os COCs são normalmente coletados de folículos antrais de tamanho médio e ainda não completaram o processo de capacitação oocitária, logo não possuem a maquinaria molecular e celular necessária para manter o início da embriogenese; e a ação mecânica de remover os COCs do folículo resulta na perda do ambiente natural inibitório da meiose, levando à maturação meiótica oocitária "espontânea" in vitro. A eficiência das tecnologias de MIV dos oócitos está limitada pelo desenvolvimento da competência intrínseca, que se refere ao estado bioquímico e molecular que permite o oócito maduro ser fertilizado normalmente e se desenvolver em um embrião, o qual, na transferência, irá permitir o desenvolvimento a termo (Gilchrist and Thompson, 2007).

Apesar das limitações do processo de MIV oocitária, esta é uma tecnologia de reprodução artificial muito valiosa que lida com uma população de oócitos muito diferente 
coletados de folículos em vários estágios do desenvolvimento, dominância e atresia (Gilchrist and Thompson, 2007). Para a PIV são coletados oócitos de folículos com tamanho entre dois e oito milímetros, os quais possuem COCs com aproximadamente o mesmo diâmetro, em torno de 100 a $120 \mu \mathrm{m}$. Após serem retirados dos ovários, os COCs são selecionados quanto sua qualidade, com base na análise de sua morfologia (disposição das células do cumulus e a aparência do ooplasma). Estes podem ser classificados em quatro categorias, de acordo com a morfologia, seguindo o método utilizado por Viana e colaboradores (2004), com adaptações. Os COCs de grau I apresentam células do cumulus compactas, contendo mais de três camadas de células, ooplasma homogêneo, de coloração marrom. Os COCS grau II apresentam de duas a três camadas de células do cumulus compactas e ooplasma homogêneo. Os COCs grau III possuem menos de duas camadas de cumulus, com parte da zona pelúcida exposta e ooplasma heterogêneo, contendo ou não, granulações. Os COCs grau IV possuem poucas células ou nenhuma célula do cumulus ao redor da zona pelúcida, citoplasma com muitas granulações, ou ainda com células do cumulus em estado apoptótico sendo, portanto, inviável de se desenvolver.

\subsection{O hormônio Anti-Mülleriano}

O AMH, também conhecido como substância inibidora Mülleriana, é uma glicoproteína pertencente à família de fatores de crescimento transformantes (TGF)- $\beta$, cuja expressão só é encontrada nas gônadas (Cate et al. 1986), e estão relacionados ao desenvolvimento folicular ovariano. Até recentemente, o AMH só era conhecido por sua função na diferenciação sexual masculina, sendo produzido pelas células de Sertoli durante a diferenciação testicular, sendo responsável pela regressão dos ductos Müllerianos (Jost, 1947), que nas fêmeas se diferenciam nos ovidutos, no útero e na parte superior da vagina. Hoje em dia sabemos que o AMH é também expresso nas fêmeas pelos ovários, depois que os ductos Müllerianos perdem a sensibilidade ao hormônio (Visser et al. 1998).

Alguns estudos demonstraram que o $\mathrm{AMH}$ está relacionado com a inibição do início do crescimento folicular, um processo também chamado de ativação folicular ou recrutamento inicial. Durlinger e colaboradores (2002) confirmaram essa conclusão através de um estudo com ovários de camundongos neonatos cultivados in vitro por 2 ou 4 dias na presença ou ausência de AMH. Os ovários de camundongos de 2 dias contêm predominantemente folículos primordiais e alguns oócitos nus, mas não possuem folículos em crescimento, logo são um ótimo modelo para investigar a influência do AMH no recrutamento de folículos 
primordiais. A presença do AMH causou uma diminuição de 40-50\% no número de folículos em crescimento depois de 2 e 4 dias de cultura quando comparados ao grupo controle, mostrando que o AMH é capaz de inibir o crescimento inicial de folículos primordiais e assim funciona como um fator de crescimento inibidor no ovário durante os estágios iniciais da foliculogênese (Durlinger et al. 2002). Esse efeito inibidor é provavelmente o resultado de um efeito parácrino do AMH derivado das células da granulosa no folículo primordial. Além disso, sabemos que o AMH não é o único regulador do recrutamento inicial. A iniciação do crescimento folicular também pode ser positivamente influenciada pelo fator de célula tronco (SCF), fator de crescimento de diferenciação 9 (GDF9), fator de crescimento de fibroblástico básico (bFGF) e fator de crescimento neuronal (NGF) (Durlinger et al., 2002), o que torna necessário novos estudos que possam demonstrar a possível interação entre esses fatores para um melhor entendimento da função de cada um.

No ovário, a expressão do AMH é restrita às células da granulosa (Monniaux et al. 2008), sendo que estas apresentam maior expressão nos folículos pré-antrais e pequenos folículos antrais, diminuindo sua expressão durante a fase final do desenvolvimento folicular, onde são selecionados para a dominância pela ação do FSH (Baarends et al. 1995). Assim, podemos dizer que o AMH é expresso em folículos que foram recrutados a partir do pool de folículos primordiais e que não foram selecionados para a dominância. Esse padrão de expressão nos indica que o AMH deve ter um importante papel na regulação do número de folículos em crescimento, assim como na seleção para a ovulação (Visser et al. 2005). Estudos de imunohistoquímica realizados por Weenen e colaboradores (2004) demonstraram expressão do AMH em folículos primários, continuando a ser expresso até os folículos nos estágios antrais, com a maior expressão sendo encontrada nas células da granulosa dos folículos secudários, pré-antrais e pequenos folículos antrais, com diminuição gradual da expressão nos folículos antrais. A expressão do $\mathrm{AMH}$ dentro desses folículos não é sempre igualmente distribuída, assim, podemos encontrar expressão folicular maior nas células da granulosa que estão ao redor do antro e do oócito (Durlinger et al. 2002; Baarends et al. 1995). Este gradiente de expressão do $\mathrm{AMH}$ dentro do folículo pode refletir diferenças funcionais entre as células da granulosa que estão mais intimamente ligadas ao oócito e as células que estão mais na periferia, como diferenças na capacidade de proliferação e atividade esteroidogênica (Baarends et al. 1995), e podem surgir sob a influência de fatores produzidos pelo oócito.

Alguns estudos demonstraram pequenas concentrações de AMH no fluido folicular de grandes folículos antrais e pré-ovulatórios (Monniaux et al. 2008), porém este assunto é um 
pouco controverso, já que existem trabalhos que relataram presença de expressão do AMH em folículos pré-ovulatórios (Hirobe et al. 1994; Ueno et al. 1989), enquanto outros demonstraram o desaparecimento da expressão do AMH a partir dos estágios antrais e avante, e sua ausência em folículos pré-ovulatórios e corpo lúteo (Baarends et al. 1995; Durlinger et al. 2002). Um estudo recente realizado por Hayashi e colaboradores (2010) encontrou diferenças no padrão de expressão quando comparados folículo dominante e seus folículos subordinados em bovinos, onde o AMH apresentou maior expressão nas células da granulosa dos folículos considerados dominantes, sugerindo uma associação deste hormônio com o estabelecimento e manutenção da dominância folicular após a seleção do mesmo. Neste mesmo estudo, após utilizar a técnica de hibridação in situ, eles demonstraram que o mRNA AMH estava claramente localizado e tinha alta expressão somente nas células da granulosa de grandes folículos saudáveis, o que implica que este fator de crescimento tem um possível efeito no desenvolvimento do folículo dominante após seleção folicular, assim como no recrutamento (Hayashi et al. 2010). Takahashi e colaboradores (2008) também demonstraram que a presença de altos níveis do AMH no fluido folicular está correlacionada com o sucesso da fertilização de oócitos pós FIV, sugerindo que o AMH pode ter um papel importante no desenvolvimento dos oócitos e fertilização.

Como membro da família TGF $\beta$, o AMH utiliza um sistema de transdução de sinal que foi identificado para os outros fatores da família. Esses fatores sinalizam através de um complexo receptores serina-tirosina quinase, que consistem de um receptor tipo II liganteespecífico e um receptor tipo I mais genérico (Visser et al. 2005). O receptor de AMH tipo II (AMHRII), que é o único receptor tipo II para o hormônio, é expresso no ovário imediatamente após o nascimento quando os folículos primordiais ainda nem foram formados e continua sendo expresso durante a vida (Durlinger et al. 2002). Este receptor não apresenta um padrão de expressão dimórfico como o $\mathrm{AMH}$, sendo encontrada expressão nas células mesenquimais dos ductos Müllerianos e gônadas de ambos os sexos (Durlinger et al.2002). Em ratos e camundongos foi demonstrado que a expressão do AMHRII colocaliza com a do AMH nas células da granulosa, mostrando um padrão de expressão similar (Baarends et al. 1995).

Em relação interação entre o $\mathrm{AMH}$ e o FSH, estudos realizados por Durlinger e colaboradores (1999) demonstraram que o AMH, em adição ao seu papel no recrutamento dos folículos primordiais, também tem uma função na sensibilidade dos folículos em crescimento ao FSH. Apesar das baixas concentrações de FSH no soro, ovários de camundongos nocaute para o AMH de quatro meses de idade continham mais folículos em crescimento quando 
comparados aos grupos selvagens, indicando que o AMH pode inibir o crescimento folicular induzido pelo FSH (Durlinger et al. 1999). O efeito inibidor do AMH em folículos estimulados por FSH também foi confirmado em um modelo in vivo, onde o crescimento de folículos na presença de altas e baixas concentrações de FSH no soro foi comparado entre fêmeas nocaute para o AMH e fêmeas selvagem (Durlinger et al. 2001), demonstrando que na ausência do $\mathrm{AMH}$, os folículos são mais suscetíveis ao FSH. Essa modulação na resposta ao FSH pelo AMH pode ser muito importante durante o processo do recrutamento cíclico, onde um grupo de folículos é recrutado do pool de grandes folículos pré-antrais e pequenos folículos antrais para continuar a crescerem até o estágio pré-ovulatório. Este recrutamento cíclico surge como uma resposta a uma segunda onda de FSH. Este pico de FSH é importante para o número de folículos que serão recrutados (Durlinger et al. 2002). Sabe-se que, dependendo do estágio do desenvolvimento, cada folículo necessita de uma certa concentração de FSH para continuar a crescer; isto é, cada folículo apresenta sua própria concentração limiar e este limiar tem que ser excedido para garantir o crescimento até o estágio pré-ovulatório (Durlinger et al. 2002), e o AMH pode ser um dos fatores envolvidos na determinação da resposta do folículo ao FSH durante o recrutamento cíclico. O papel do AMH no recrutamento cíclico é apoiado pelo seu padrão diferencial de expressão observado em grandes folículos pré-antrais e pequenos folículos antrais (Baarends et al. 1995). Apesar desses folículos serem morfologicamente indistinguíveis, alguns folículos apresentam maior expressão de $\mathrm{AMH}$ do que outros. A baixa expressão do $\mathrm{AMH}$ estaria correlacionada com o aumento da sensibilidade ao FSH, permitindo que esses folículos sejam selecionados para continuar o crescimento e ovulação até o próximo ciclo.

Em vista da importância do AMH no desenvolvimento folicular, e seleção dos oócitos, e do conhecimento que a ação deste hormônio traria às práticas de reprodução assistida, nós avaliamos neste trabalho a influência da adição do AMH ao meio de maturação de oócitos bovinos de diferentes qualidades morfológicas, verificando se houve modificação na taxa de desenvolvimento dos oócitos em blastocistos após fertilização in vitro, além de modificações no padrão de expressão do RNA mensageiro (mRNA) de genes correlacionados com sua ação, como o AMHRII e o FSHR (receptor de FSH) nos oócitos, além do AMH nas células da granulosa. 
Objetivos 


\section{OBJETIVOS}

\subsection{Objetivo geral}

Avaliar a influência da adição do hormônio Anti-Mülleriano ao meio de maturação in vitro de oócitos bovinos.

\subsection{Objetivos específicos}

Avaliar a produção in vitro de embriões por meio do desenvolvimento de blastocistos obtidos pela técnica de fertilização in vitro após a adição de hormônio Anti-Mülleriano ao meio de maturação de oócitos provenientes de COCs grau I, grau II e grau III

Avaliar a expressão relativa de mRNA dos genes AMHRII e FSHR em oócitos provenientes de COCs graus I, II e III maturados em diferentes concentrações do Hormônio Anti-Mülleriano.

Avaliar a expressão relativa de mRNA dos genes AMHRII e FSHR em AMH em células da granulosa provenientes de COCs graus I, II e III maturados em diferentes concentrações do Hormônio Anti-Mülleriano. 
Material e Métodos 


\section{MATERIAL E MÉTODOS}

\subsection{Produção de embriões in vitro}

\subsubsection{Coleta de oócitos e Maturação in vitro}

Os ovários foram coletados de fêmeas bovinas abatidas em frigorífico e armazenados previamente em solução salina $(\mathrm{NaCl}$ 0,9\%) estéril contendo antibióticos (penicilina $100 \mathrm{UI} / \mathrm{ml}$, estreptomicina $50 \mathrm{mg} / \mathrm{ml}$ ), em recipiente térmico a $35^{\circ} \mathrm{C}$ para transporte até o Laboratório de Micromanipulação de Embriões e Molecular (LMEM) do Departamento de Genética, FMRP - USP. Chegando ao laboratório, os ovários foram lavados e armazenados em nova solução salina a $35^{\circ} \mathrm{C}$ e em seguida, seus folículos medindo entre 2 e $8 \mathrm{~mm}$ foram aspirados utilizando-se uma seringa de $10 \mathrm{ml}$ acoplada a uma agulha de calibre $18 \mathrm{G}$. O líquido folicular foi depositado em Placas de Petri, mantidas sobre uma placa aquecedora $\left(35^{\circ} \mathrm{C}\right)$, para posterior seleção dos complexos cumulus-oócito (COCs) sobre o estereomicroscópio (aumento 40X).

A seleção dos COCs foi realizada de acordo com suas características morfológicas, sendo separados em grau I, grau II e grau III (Le Guienne, 1998) (Figura 1).

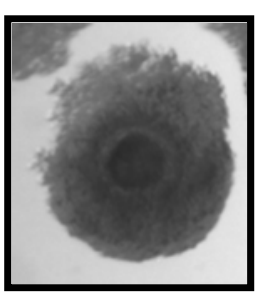

Grau 1

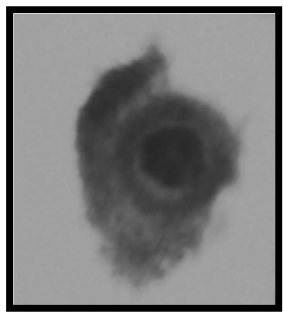

Grau 2

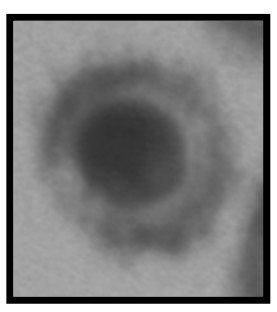

Grau 3

Figura 3. Classificação dos COCs em graus I, II e III de acordo com sua morfologia (diâmetro do oócito $\sim 120 \mu \mathrm{m}$ ) (arquivo de fotos do LMEM) (aumento 40X). 
Após a seleção, os COCs foram lavados duas vezes em meio de lavagem tamponado TCM199 ${ }^{\circledR}$-HEPES com sais Earle e bicarbonato (Gibco Laboratory, GrandIsland, NY, USA) suplementado com 0,2mM de piruvato (Sigma Chemical Co., St Louis, MO, USA), 50g/ml de gentamicina (Sigma), 10\% de Soro Fetal Bovino (SFB - Sigma) e, posteriormente, lavados duas vezes em meio de maturação TCM199 ${ }^{\circledR}$ suplementado com $0,2 \mathrm{mM}$ de piruvato, $50 \mu \mathrm{g} / \mathrm{ml}$ de gentamicina, $10 \%$ de SFB, $0,5 \mu \mathrm{g} / \mathrm{ml}$ de hormônio folículo estimulante (FSH - Folltropin ${ }^{\circledR}$ $\mathrm{V}$, Bioniche, Canadá), $50 \mu \mathrm{g} / \mathrm{ml}$ de gonadotrofina coriônica humana (Chorulon ${ }^{\circledR} 5000 \mathrm{UI}$ Intervet Internacional B.V., Holanda) (possui atividade de hormônio luteinizante) e $1 \mu \mathrm{g} / \mathrm{ml}$ de estradiol (Sigma) . Após a lavagem, os COCs foram transferidos para Placas de Petri descartáveis de $35 \mathrm{~mm}$, contendo microgotas de $100 \mu 1$ de meio maturação, cobertas por óleo mineral (Sigma), previamente equilibradas em atmosfera contendo $5 \%$ de $\mathrm{CO}_{2}$ por no mínimo 2 horas. Foram colocados no máximo $20 \mathrm{COCs} /$ microgota. Essa placa foi levada à incubadora a $38,7^{\circ} \mathrm{C}$, atmosfera de $5 \%$ de $\mathrm{CO}_{2}$ em ar e umidade saturada, onde foi mantida por um período de 22-24 horas, permitindo a capacitação e maturação oocitária (Figura 2).

Para os COCs que foram maturados na presença de $10 \mathrm{ng} / \mathrm{ml}, 50 \mathrm{ng} / \mathrm{ml}, 150 \mathrm{ng} / \mathrm{ml}$ ou 300ng/ml de hormônio Anti:Mülleriano (R\&D Systems - Recombinant Human MIS), foram preparadas placas contendo microgotas de meio de maturação acrescido das diferentes concentrações propostas do hormônio. A maturação procedeu nas mesmas condições descritas para o grupo controle.

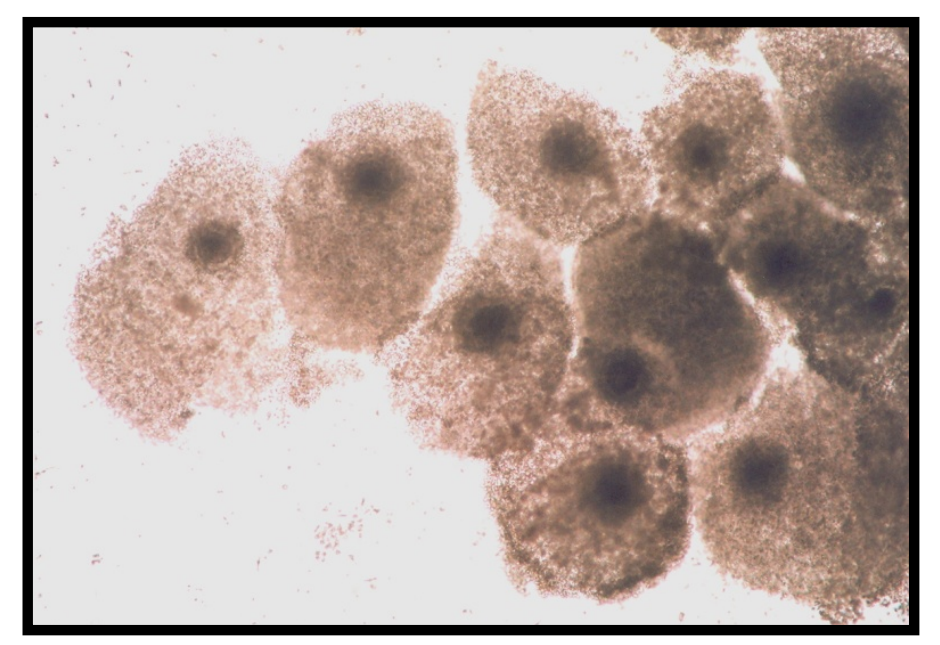

Figura 4. Complexo cumulus-oócitos grau 1 após $24 \mathrm{~h}$ de maturação in vitro (arquivo de fotos do LMEM). 


\subsubsection{Seleção de espermatozóides e ajuste da concentração espermática}

As palhetas de sêmen do touro utilizado foram descongeladas em banho-maria a $35^{\circ} \mathrm{C}$, durante 30 segundos e o conteúdo submetido à técnica de gradiente Percoll ${ }^{\circledR}$ (Sigma) para a obtenção de espermatozóides móveis, além da remoção do diluidor do sêmen e do plasma seminal. Para tanto, o sêmen de uma palheta foi depositado sobre o gradiente de Percoll $^{\circledR} \mathrm{em}$ concentrações de 45\% e 90\% (2ml: $2 \mathrm{ml})$ preparado com o meio de lavagem de espermatozóide TALP - Sêmen 1X ( NaCl 114mM, KCl 3,22mM, $\mathrm{NaH}_{2} \mathrm{PO}_{4}$ 0,34mM, $\mathrm{NaHCO}_{3} 25 \mathrm{mM}$, lactato de sódio $60 \% 16 \mathrm{mM}, \mathrm{CaCl}_{2} \cdot 2 \mathrm{H}_{2} 02 \mathrm{mM}, \mathrm{MgCl}_{2} \cdot 6 \mathrm{H}_{2} \mathrm{O} 0,5 \mathrm{mM}$ e BSA - Bovine serum albunin) e submetido à centrifugação por 30 minutos a $700 \mathrm{~g}$. Após esse período, o sobrenadante foi descartado e o pellet avaliado quanto à concentração espermática e motilidade, retirando-se duas amostras de $5 \mu 1$ as quais foram diluídas em $250 \mu 1$ de água e $250 \mu \mathrm{l}$ de meio de fertilização TALP suplementado com $10 \mu \mathrm{g} / \mathrm{ml}$ heparina, $50 \mu \mathrm{g} / \mathrm{ml}$ piruvato, $50 \mu \mathrm{g} / \mathrm{ml}$ gentamicina, $6 \mathrm{mg} / \mathrm{ml} \mathrm{BSA} \mathrm{com} \mathrm{ausência} \mathrm{de} \mathrm{ácidos} \mathrm{graxos} \mathrm{e} \mathrm{solução} \mathrm{de}$ PHE ( $2 \mu \mathrm{M}$ de penicilina, $1 \mu \mathrm{M}$ de hipotaurina e $0,25 \mu \mathrm{M}$ de epinefrina), respectivamente.

A taxa de motilidade espermática foi obtida sob visualização em microscópio e a concentração espermática por meio da contagem do número de espermatozóides nos 5 quadrantes maiores da Câmera de Neubauer. O ajuste final da concentração espermática foi feito pela adição de um volume de meio de fertilização ao pellet obtido pela equação:

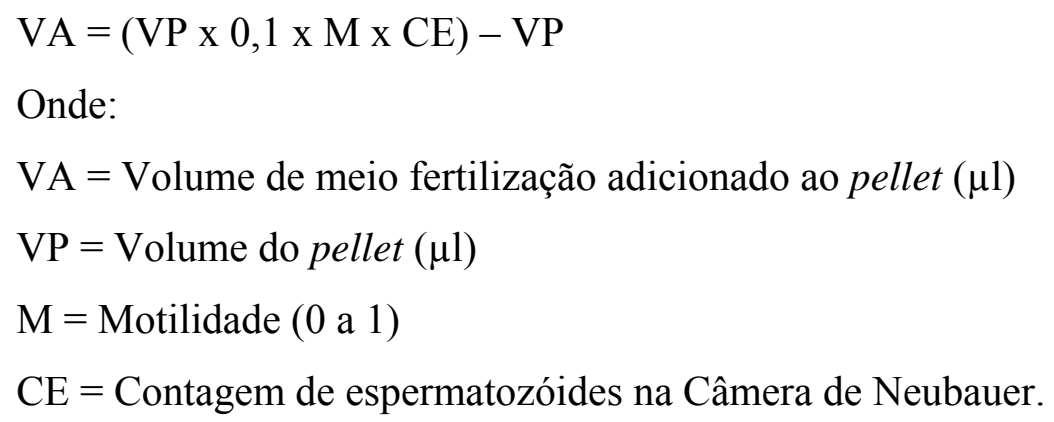

\subsubsection{Capacitação espermática e Fecundação in vitro}

Para a indução da capacitação espermática foram adicionados $10 \mu 1$ de solução de espermatozóides, previamente ajustada, as microgotas de $90 \mu 1$ de meio de fertilização, cobertas com óleo mineral, para obtenção de uma concentração final de 2 milhões de espermatozóides por $\mathrm{ml}$.

Após 15 minutos de capacitação, os oócitos supostamente maduros (no estágio da metáfase da segunda meiose) foram transferidos para as microgotas. Os espermatozóides e os 
oócitos permaneceram sob incubação em atmosfera com $5 \%$ de $\mathrm{CO}_{2}$ em ar a $38,7^{\circ} \mathrm{C}$ durante 12 horas (Figura 3).

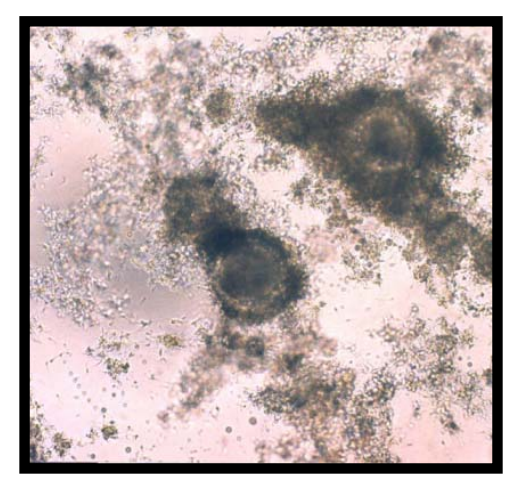

Figura 5. Interação entre espermatozóides e oócitos após 12 horas (arquivo de fotos do LMEM).

\subsubsection{Cultivo in vitro}

Após o período de incubação, os supostos zigotos foram lavados e submetidos a pipetagem em meio de fertilização para retirada do excesso de células do cumulus e de espermatozóides aderidos, restando em torno de 3 camadas de células do cumulus aderidas à zona pelúcida. Os zigotos foram co-cultivados com monocamadas de células do cumulus em microgotas de 50 $\mu 1$ de meio de cultivo (meio CR2aa - Rosenkrank and First, 1994) cobertas com óleo mineral por 168 horas em atmosfera com $5 \%$ de $\mathrm{CO} 2 \mathrm{em}$ ar a $38,7^{\circ} \mathrm{C}$, e umidade saturada.

No quarto dia após a FIV, foram retirados da placa os excessos de células do cumulus e os embriões inviáveis ou em estágios atrasados, permanecendo apenas os embriões que possuíam de 16 a 32 células. O número de embriões viáveis foi contabilizado, e foi realizada a substituição de $30 \mu 1$ de meio CR2aa em cada microgota para a refrescagem do meio de cultivo (feeding).

\subsubsection{Classificação dos embriões viáveis}

Após 168 horas da FIV (sétimo dia de cultivo in vitro), o número de embriões viáveis foi avaliado e os embriões classificados. Foram considerados embriões viáveis as estruturas que se encontravam nos seguintes estágios de desenvolvimento: 
- Blastocisto inicial (Bi): blastocisto iniciando o processo de cavitação sendo que a cavidade ocupa menos da metade do volume total do embrião,

- Blastocisto (B1): cavidade sendo expandida e ocupando metade ou mais do volume total, está ocorrendo redução do botão embrionário,

- Blastocisto expandido $(\mathrm{Bx})$ : zona pelúcida delgada, botão embrionário reduzido em relação à cavidade expandida.

- Blastocisto eclodido (Be): blastocisto eclodindo ou fora da zona pelúcida.

Os embriões viáveis podem ser observados na figura 4.
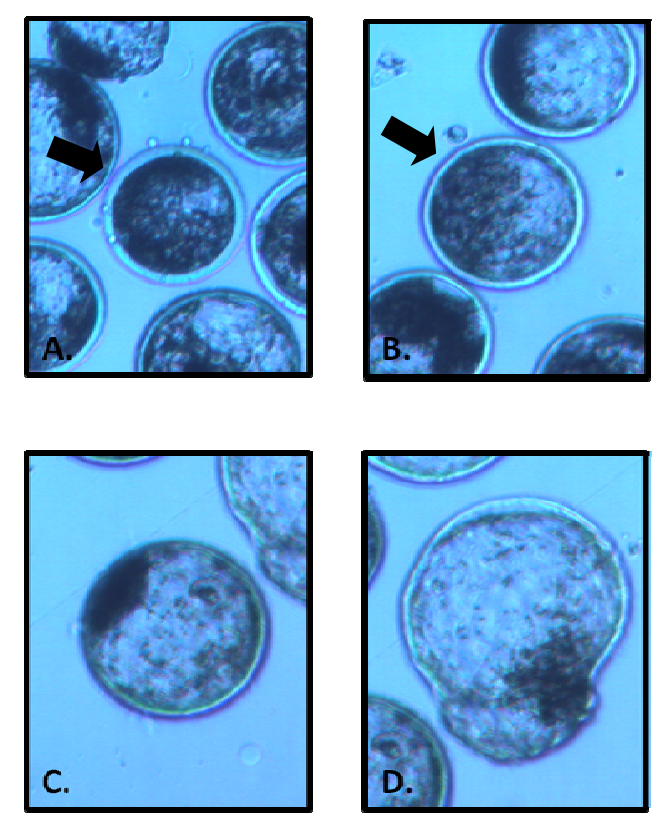

Figura 6. Embriões viáveis ao sétimo dia de desenvolvimento após fertilização in vitro. A. Blastocisto inicial (Bi) iniciando a formação da blastocele; B. Blastocisto (Bl) com a cavidade expandindo ocupando metade do volume ou mais do embrião, com início da formação do botão embrionário; C. Blastocisto expandido (Bx) com zona pelúcida delgada, cavidade bastante desenvolvida e botão embrionário reduzido; D. Blastocisto eclodido $(\mathrm{Be})$ com ruptura da zona pelúcida e processo de eclosão embrionária (aumento 100X) (arquivo de fotos do LMEM).

Para minimizar possíveis fontes de variações ambientais, os meios utilizados para maturação dos oócitos, seleção e capacitação espermática, fecundação e cultivo dos embriões foram padronizados para todos os experimentos, segundo protocolos do Laboratório de Micromanipulação de Embriões, FMRP - USP. Além disso, foi escolhido o sêmen de um único touro, com o intuito de também minimizar efeitos externos na avaliação da produção de blastocistos. 


\subsection{Análise quantitativa de expressão gênica por meio da reação em cadeia da polimerase em tempo real em COCs maturados na presença ou ausência do AMH}

\subsubsection{Coleta de oócitos e maturação in vitro}

A coleta dos oócitos e maturação dos mesmos foi realizada conforme descrito no item 3.1.1.

\subsubsection{Remoção das células do cumulus dos COCs}

Foram utilizados os COCs de diferentes qualidades morfológicas (graus I, II e III). Após maturação in vitro conforme descrito no item 3.1.1, esses COCs foram submetidos ao procedimento de desnudamento através do uso da enzima hialuronidase 0,2\% (Hyaluronidase Type IV-S, Sigma). Para tanto, os COCs foram lavados três vezes em meio de lavagem tamponado para retirada do óleo presente nas placas, e em seguida as células da granulosa e o oócito foram separados através de agitação dos COCs no vortex por 3 minutos em uma solução de 0,002g de hialuronidase/ml (protocolo modificado de Izadyar et al, 1999). Os oócitos foram então separados das células da granulosa, lavados em solução de PBS $1 \mathrm{X}$ (Phosphate buffer saline - $\mathrm{NaCl}$ 8,0 g/L; KCl 0,2 g/L, $\mathrm{Na}_{2} \mathrm{HPO}_{4}$ 1,44 g/L; $\mathrm{KH}_{2} \mathrm{PO}_{4}$ 0,22 g/L e $\mathrm{pH} 7,0)$ e armazenados em grupos de $20-30$ oócitos à $-80^{\circ} \mathrm{C}$ até a extração do RNA total. As células da granulosa também foram lavadas em PBS $1 \mathrm{X}$ e armazenadas à $-80^{\circ} \mathrm{C}$.

\subsubsection{Extração do RNA total de oócitos e células da granulosa}

O RNA total do oócitos e células da granulosa foi extraído utilizando-se o RNeasy Micro Kit (Qiagen ${ }^{\circledR}$ Samples \& Assays Technologies, Valencia, California, USA), segundo especificações do fabricante. Resumindo, as células foram rompidas através da adição de $75 \mu 1$ de tampão RLT, seguida de agitação por um minuto. Em seguida, foi adicionado um volume de etanol $70 \%$ ao lisado, o qual foi misturado por pipetagem. A amostra foi transferida para uma coluna e em seguida foi submetida à centrifugação por 15 segundos a $10.000 \mathrm{rpm}$. Após descarte do lavado, foi adicionado $350 \mu 1$ do tampão RW1 à coluna, que foi novamente submetida à centrifugação por 15 segundos, á $10.000 \mathrm{rpm}$. Foi adicionado uma solução de $10 \mu 1$ de DNase I em $70 \mu 1$ de tampão RDD ao centro da coluna, a qual ficou à temperatura ambiente por 15 minutos. Decorrido este tempo, foi adicionado mais $350 \mu 1$ de tampão RW1 á 
coluna, a qual foi novamente submetida à centrifugação. Logo após, foi adicionado $500 \mu 1$ de tampão RPE à coluna, sendo realizada uma nova centrifugação. E finalmente foi adicionado $500 \mu 1$ de etanol 80\% para lavar a coluna, sendo que o RNA foi coletado após a adição de $14 \mu 1$ de água livre de RNase, por centrifugação. O RNA extraído dos oócitos não foi quantificado devido à baixa concentração do mesmo, sendo utilizado $12 \mu 1$ do RNA total para a síntese do DNA complementar (cDNA). O RNA das células da granulosa foi quantificado utilizando-se o Nanodrop ND-2000, porém, como a quantidade de RNA também era menor do que a recomendada pelo fabricante para uso com o kit de síntese de cDNA, também foi utilizado $12 \mu 1$ do RNA total obtido na extração para a síntese do cDNA.

\subsubsection{Síntese de DNA complementar (cDNA)}

Tendo como molde o RNA total, a síntese do DNA complementar (cDNA) foi realizada utilizando-se o High Capacity cDNA Reverse Transcription Kit (Applied Biosystems, Warrington, UK), segundo especificações do fabricante. Resumidamente, foram utilizados dNTPs, iniciadores, e transcriptase reversa, juntamente com o RNA. A reação foi incubada no termociclador por 10 minutos a $25^{\circ} \mathrm{C}$, seguidos por 120 minutos a $37^{\circ} \mathrm{C}$, completando o ciclo com 5 minutos à $85^{\circ} \mathrm{C}$. Após a reação, o cDNA foi quantificado utilizando-se o Nanodrop ND-2000. O cDNA fita simples foi estocado a $-20^{\circ} \mathrm{C}$ até o uso na reação de PCR em tempo real.

\subsubsection{Pré amplificação do cDNA de oócitos}

As amostras de cDNA oócitos foram pré amplificadas utilizando-se o TaqMan $^{\circledR}$ PreAmp Master Mix Kit (Applied Biosystems), conforme especificações do fabricante. Resumidamente, primeiro foi feito um pool com todos os ensaios TaqMan ${ }^{\circledR}$ (AMHRII, FSHR e GAPDH - tabela 1) que seriam analisados, o qual foi diluído em água ultra pura, sendo que cada ensaio ficou em uma concentração final de 0,2X. Em seguida, a reação de pré amplificação foi montada utilizando-se $25 \mu 1$ de TaqMan $^{\circledR}$ PreAmp Master Mix, 12,5 $\mu 1$ do pool de ensaios $(0,2 \mathrm{X}), 12,5 \mu \mathrm{l}$ de amostra de cDNA $(80 \mathrm{ng} / \mu \mathrm{l})$. A reação foi incubada no termociclador por 10 minutos à $95^{\circ} \mathrm{C}$, seguidos por 14 ciclos de 15 segundos à $95^{\circ} \mathrm{C}$ e 4 minutos à $60^{\circ} \mathrm{C}$. As reações de $\mathrm{PCR}$ em tempo real foram realizadas utilizando o produto desta pré amplificação, diluído em um volume de 1:3. 


\subsubsection{Estudo da expressão gênica por PCR em Tempo Real}

As amostras foram quantificadas com relação à sua expressão gênica no aparelho $A B I$ PRISM $^{T M} 7500$ Sequence Detection Systems (Applied Biosystems). As reações foram executadas utilizando o sistema TaqMan ${ }^{\circledR}$ Gene Expression Assays (TaqMan ${ }^{\circledR}$ MGB probes, FAM ${ }^{\mathrm{TM}}$ dye-labeled) da Applied Biosystems. Os ensaios utilizados estão apresentados na tabela 1. Segundo o fabricante, todos os ensaios de expressão gênica TaqMan ${ }^{\circledR}$ apresentam eficiência de amplificação de $100 \%$.

Tabela 1. Ensaios TaqMan ${ }^{\circledR}$ de expressão gênica para PCR em tempo real utilizados neste trabalho. AMH e GAPDH - Assay-on-Demand ${ }^{\mathrm{TM}}$ Gene Expression Products e AMHRII e FSHR - Custom TaqMan ${ }^{\circledR}$ Assays.

\begin{tabular}{cc}
\hline Gene Alvo & Taqman $_{\text {®_ Gene Expression Assay ID }}$ \\
\hline AMH & Bt03222835_g1 \\
AMHRII & AIMSGQ1 \\
FSHR & AIN1EW9 \\
\hline Controle endógeno & \\
\hline GAPDH & Bt03218916_g1 \\
\hline
\end{tabular}

Todos os procedimentos experimentais foram conduzidos de acordo com as especificações dos ensaios TaqMan ${ }^{\circledR}$ (Applied Biosystems) para análise da expressão gênica e da metodologia do sistema de detecção. A PCR em Tempo Real foi realizada em triplicata para cada amostra conforme as instruções do fabricante, nas seguintes condições: $10 \mu \mathrm{L}$ do TaqMan ${ }^{\circledR}$ Universal PCR Master Mix (2x) (Applied Biosystems), 1,0 $\mu \mathrm{L}$ de sonda, 4,0 $\mu \mathrm{L}$ de $\mathrm{H}_{2} \mathrm{O}$ ultrapura e 5,0 $\mu \mathrm{L}$ de cDNA pré-amplificado diluído (diluição de $1 / 3$ ) em volume final de $20 \mu \mathrm{L}$. As condições da reação foram $95^{\circ} \mathrm{C}$ por 10 minutos seguidos de 40 ciclos a $95^{\circ} \mathrm{C}$ por 15 segundos e $60^{\circ} \mathrm{C}$ por 1 minuto. Nas reações utilizando-se as células da granulosa, foram utilizados $1.000 \mathrm{ng}$ por reação.

O nível de expressão (RQ) para os genes analisados foi calculado para cada amostra de acordo com o método de $2^{-\Delta \Delta C T}$ (ou 2-Ct), descrito previamente no Applied Biosystems User Bulletin \# 2 (PN 4303859) (Applied Biosystems) e citado na literatura (Schmittgen et al. 2000). O gene GAPDH (controle endógeno) foi utilizado como normalizador para os cálculos do $2^{-\Delta \Delta C T}$. 


\section{Cálculo}

$\triangle C \mathrm{~T}_{\text {amostra }}=$ (média do $\mathrm{CT}$ gene amostra - média ${ }_{G A P D H}$ amostra $)$

$\triangle C \mathrm{~T}_{\text {calibrador }}=\left(\right.$ média do $\mathrm{CT}$ gene calibrador - média $\left.{ }_{\text {GAPDH calibrador }}\right)$

$\Delta \Delta C \mathrm{~T}=\left(\Delta C \mathrm{~T}_{\text {amostra }}-\Delta C \mathrm{~T}_{\text {calibrador }}\right)$

$$
\mathbf{R Q}=\mathbf{2}^{-\Delta \Delta C T}
$$

\subsection{Análise Estatística}

Para a análise estatística do desenvolvimento de embriões totais, para cada classe de oócito (graus I, II e III), maturados nas diferentes concentrações de AMH, foram montadas tabelas de contingência e aplicado o teste de Qui-quadrado sob a hipótese nula de independência entre os fatores considerados e a taxa de fecundação, sendo adotado o nível de significância de 5\%. O procedimento FREQ do pacote estatístico SAS (SAS ${ }^{\circledR}$, Versão 9.2) foi utilizado para realização destas análises.

Para as análises de expressão relativa do mRNA dos genes escolhidos foi utilizado o programa GraphPad Prism (versão 5.0 GraphPad Software Inc., San Diego, CA, EUA). As diferenças significativas na expressão dos genes entre as células cultivadas com diferentes concentrações de AMH foram avaliadas com o teste Kruskal-Wallis, utilizando o valor obtido para a expressão gênica, sendo adotado o nível de significância de 5\%. 
Resultados e Discussão 


\section{RESULTADOS E DISCUSSÃO}

\subsection{A adição do hormônio anti-Mülleriano ao meio de maturação influencia na produção in vitro de embriões bovinos}

Para verificar a influência do AMH na produção in vitro de embriões viáveis foram utilizados 4.949 COCs obtidos de ovários de animais abatidos em matadouro. Após a aspiração dos COCs em laboratório, os mesmo foram selecionados e separados em graus I, II e III, de acordo com suas características morfológicas (Le Guienne, 1998) (Figura 3). Foram utilizados 1.902 COCs grau I; 1.548 COCs grau II e 1.499 COCs grau III.

Os COCs foram submetidos à maturação in vitro por 24 horas na ausência (controle negativo) e presença de 10, 50, 150 e $300 \mathrm{ng} / \mathrm{ml}$ de $\mathrm{AMH}$, adicionados ao meio de maturação. As concentrações do hormônio utilizadas neste trabalho foram escolhidas com base no estudo de Carlsson e colaboradores (2006). A adição do AMH ao meio de maturação se deu uma vez que este pertence à família de fatores de crescimento transformantes (TGF $\beta$ ), que estão relacionados com o desenvolvimento folicular ovariano (Knight and Gliser, 2006), além de sua relação com o sucesso da fertilização dos oócitos durante o processo de fertilização in vitro em humanos (Takahashi et al. 2008). Após o período de maturação, os COCs foram submetidos à técnica de FIV e 168 horas depois da fertilização (sétimo dia de cultivo in vitro), o número de embriões viáveis foi avaliado e os embriões classificados de acordo com suas características morfológicas. Os números de COCs utilizados nas diferentes concentrações de AMH e no grupo controle diferiram de acordo com a disponibilidade dos COCs nos dias dos experimentos.

A análise estatística do desenvolvimento de embriões totais por oócito, utilizando as diferentes qualidades morfológicas dos COCs (graus I, II, III) maturados nas diferentes concentrações do AMH $(0,10,50,150$ e $300 \mathrm{ng} / \mathrm{ml})$, foi realizada aplicando-se o teste de Quiquadrado às tabelas de contingência montadas para todos os resultados. Após análise testando os 15 níveis (3 graus de oócitos x 5 concentrações de hormônio) foi obtido um resultado significativo $(\mathrm{p}<0.0001)$, o que indica haver diferenças na proporção de embriões produzidos em função da classificação do oócito e ou da adição de AMH ao meio de maturação. Esses resultados mostraram que para os oócitos obtidos de COCs grau I, havia independência entre a taxa de fertilização e as diferentes concentrações de hormônio utilizadas ( $\mathrm{p}=0.5758$ ), isto é, a adição do hormônio ao meio de maturação não provocou efeito na produção de embriões. Conforme demonstrado na tabela 2, a maior diferença observada entre os embriões viáveis ocorreu quando utilizados COCs grau I maturados na presença de 150ng/ml AMH (43.61\%) comparados ao grupo controle (37.57\%), porém essa diferença não foi significativa. 
Tabela 2. Produção de embriões in vitro utilizando oócitos provenientes de COCs grau I, em diferentes concentrações de AMH.

\begin{tabular}{llllll}
\hline & GI 0 & GI 10 & GI 50 & GI 150 & GI 300 \\
\hline Oócitos não fertilizados/ embriões inviáveis & 633 & 184 & 157 & 75 & 132 \\
& $62.43 \%$ & $63.45 \%$ & $60.38 \%$ & $56.39 \%$ & $64.39 \%$ \\
\hline Embriões viáveis & 381 & 106 & 103 & 58 & 73 \\
& $37.57 \%$ & $36.55 \%$ & $39.62 \%$ & $43.61 \%$ & $35.61 \%$ \\
\hline TOTAL & 1014 & 290 & 260 & 133 & 205 \\
\hline
\end{tabular}

A análise estatística utilizando os dados obtidos quando utilizados COCs grau II e III, mostrou que houve associação significativa ( $\mathrm{p}=0.0007$ e $\mathrm{p}=0.0083$, respectivamente), indicando que a adição do AMH provocou um efeito positivo na produção dos embriões. Como pôde ser observado nas tabelas 3 e 4, o grupo de COCs maturado na presença de $150 \mathrm{ng} / \mathrm{ml}$ para os dois graus estudados apresentou um aumento na porcentagem de embriões viáveis quando comparados com o grupo controle $(53.42 \%$ x $34.71 \%$ para COCs grau II e $43.40 \%$ x $26.91 \%$ para COCs grau III).

Tabela 3. Produção de embriões in vitro utilizando oócitos provenientes de COCs grau II, em diferentes concentrações de AMH.

\begin{tabular}{llllll}
\hline & GII 0 & GII 10 & GII 50 & GII 150 & GII 300 \\
\hline Oócitos não fertilizados/ embriões inviáveis & 536 & 121 & 108 & 68 & 141 \\
& $65.29 \%$ & $61.73 \%$ & $65.06 \%$ & $46.58 \%$ & $64.38 \%$ \\
\hline Embriões viáveis & 285 & 75 & 58 & 78 & 78 \\
& $34.71 \%$ & $38.27 \%$ & $34.94 \%$ & $53.42 \%$ & $35.62 \%$ \\
\hline TOTAL & 821 & 196 & 166 & 146 & 219 \\
\hline
\end{tabular}

Tabela 4. Produção de embriões in vitro utilizando oócitos provenientes de COCs grau III, em diferentes concentrações de AMH.

\begin{tabular}{llllll}
\hline & GIII 0 & GIII 10 & GIII 50 & GIII 150 & GIII 300 \\
\hline Oócitos não fertilizados/ embriões inviáveis & 565 & 130 & 157 & 60 & 135 \\
& $73.09 \%$ & $68.78 \%$ & $67.67 \%$ & $56.60 \%$ & $67.84 \%$ \\
\hline Embriões viáveis & 208 & 59 & 75 & 46 & 64 \\
& $26.91 \%$ & $31.22 \%$ & $32.33 \%$ & $43.40 \%$ & $32.16 \%$ \\
\hline TOTAL & 773 & 189 & 232 & 106 & 199 \\
\hline
\end{tabular}

A partir desses dados, uma nova análise foi realizada com o intuito de comparar os resultados obtidos a partir dos COCs maturados nas diferentes concentrações do AMH com o grupo controle, e verificar se essas diferenças eram significativas. Os resultados demonstram que houve uma diferença significativa no desenvolvimento de embriões ao sétimo dia de cultivo in vitro quando os COCs foram maturados na presença de $150 \mathrm{ng} / \mathrm{ml}$ de $\mathrm{AMH}$ 
$(\mathrm{p}<0.001$ para COCs grau II e $\mathrm{p}=0.0004$ para COCs grau III) (Figura 7). Essa melhora na taxa de produção de blastocistos como um efeito do AMH também foi vista por Takahashi e colaboradores (2008), que associaram maiores concentrações de AMH nos folículos com o sucesso na fertilização pós FIV em humanos. Fanchin e colaboradores (2007) também verificaram a influencia do $\mathrm{AMH}$ presente nos folículos com a implantação embrionária, sugerindo que o AMH tem um papel muito importante no desenvolvimento e fertilização de oócitos, conforme também observado em nossos resultados.

A. Grau II

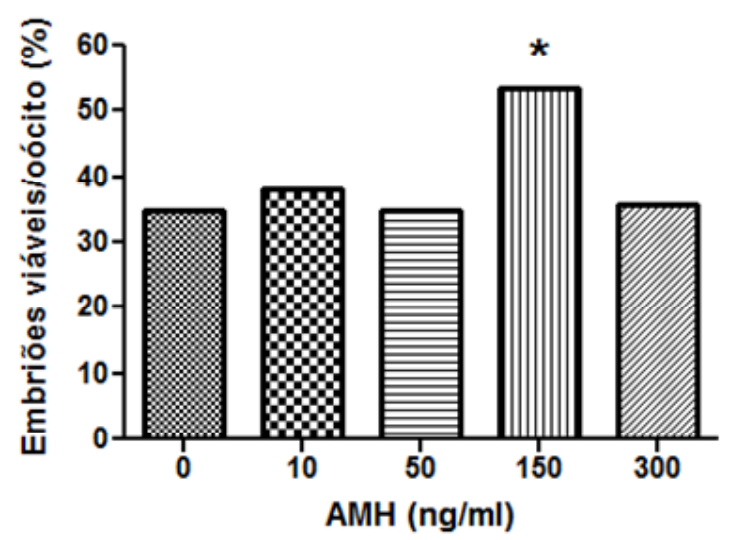

B. Grau III

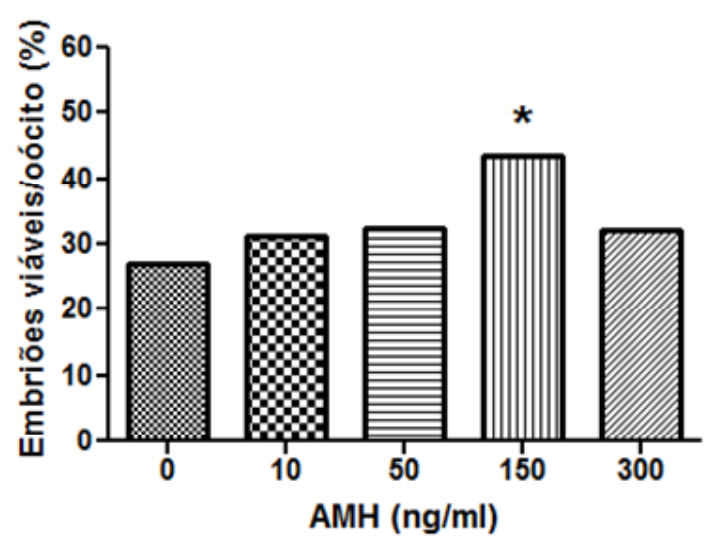

Figura 7. Porcentagem de embriões desenvolvidos ao sétimo dia de cultivo in vitro (número de embriões/número e oócitos) para COCs grau II e III, maturados nas diferentes concentrações de AMH. A análise do Qui-quadrado mostrou que houve diferença significativa quando os COCs foram maturados na presença de 150ng/ml de AMH para as duas qualidades morfológicas (graus II e III) $\left({ }^{*}\right) \mathrm{p}<0.05$.

O fato dos oócitos obtidos a partir de COCs grau I não demonstrarem diferença significativa na produção de embriões após serem maturados na presença de diferentes concentrações de AMH pode ser explicado com base na qualidade morfológica dos COCs utilizados. Os COCs grau I possuem mais células da granulosa ao redor do oócito do que os COCs graus II e III, e já é sabido que essas células são as responsáveis pela produção de vários fatores que influenciam o oócito, incluindo o AMH. Também foi demonstrado que a retirada de células do cumulus reduz abruptamente as taxas de fertilização (Hashimoto et al. 1998; Tanghe et al. 2003). Assim, COCs contendo menos células do cumulus ao redor do oócito podem ser beneficiados pela adição de hormônio ao meio de maturação, o que explica um aumento significativo na produção de embriões para oócitos oriundos de COCs graus II e III. Já os COCs grau I, por possuírem as células da granulosa ao redor de todo o oócito, em um número adequado, não seriam influenciados pela adição do $\mathrm{AMH}$. Para as outras concentrações do $\mathrm{AMH}$ utilizadas neste trabalho (10, 50 e $300 \mathrm{ng} / \mathrm{ml})$, não foi observada diferença significativa quando comparados 
ao grupo controle. É possível que altas concentrações de AMH possam ter um efeito (down regulation) na regulação do receptor do $\mathrm{AMH}$, o que pode fazer com que o tratamento se torne ineficiente com o tempo. Um estudo realizado por Carlsson e colaboradores (2006) obteve resultados similares aos nossos. Eles verificaram que a adição de $100 \mathrm{ng} / \mathrm{ml}$ de $\mathrm{AMH}$ ao meio de cultivo de tecido ovariano suprimia o inicio do crescimento de folículos primordiais, porém, quando utilizaram 300ng/ml, este efeito não foi verificado, mostrando que o $\mathrm{AMH}$ pode ter um efeito diferente, dependendo da concentração utilizada.

Hayashi e colaboradores (2010) associaram o AMH com o estabelecimento e manutenção da dominância folicular. Mesmo não sendo bem entendido o papel funcional do AMH nos folículos antrais, estudos recentes mostraram que tanto a concentração intrafolicular de AMH, quanto a concentração do mRNA AMH são maiores em folículos antrais pequenos e então diminuem com o crescimento folicular (Skinner et al. 2008; Monniaux el al. 2008; Rico et al. 2009). Dessa maneira, podemos dizer que a presença do AMH nos folículos dominantes pode estar envolvida no recrutamento e/ou seleção dos mesmos, onde os oócitos estariam aptos a se desenvolverem em embriões viáveis, e consequentemente, em indivíduos saudáveis. Nossos resultados apóiam a idéia de que existe uma ligação entre a capacidade das células da granulosa produzir AMH e a qualidade funcional do oócito, retratada por sua competência em se tornar um embrião, uma vez que demonstram que uma maior concentração de AMH ao redor do oócito melhora a produção de blastocistos em oócitos provenientes de COCs graus II e III. Logo podemos admitir que a adição deste hormônio ao meio de maturação de oócitos poderia ajudar os mesmos a progredirem no processo de maturação e subsequente desenvolvimento embrionário. Estudos que demonstram a diminuição da expressão do mRNA AMH em folículos atrésicos quando comparados com folículos saudáveis (Rico et al. 2009) complementam nossa hipótese, demonstrando a importância do AMH no desenvolvimento e seleção folicular.

\subsection{A expressão relativa de mRNA dos genes AMHRII e FSHR em oócitos e dos genes} AMH, AMHRII e FSHR em células da granulosa não sofre influência do hormônio antiMülleriano quando adicionado ao meio de maturação de COCs de diferentes qualidades morfológicas

$\mathrm{Na}$ análise de expressão relativa de mRNA dos genes AMHRII e FSHR nos oócitos maturados nas diferentes concentrações de $\mathrm{AMH}(10,50,150$ e $300 \mathrm{ng} / \mathrm{ml})$ foram utilizados três pools diferentes com 20 oócitos cada para cada um dos grupos: COCs graus 
I, II e III. Cada pool de oócitos foi coletado em dias diferentes, contendo oócitos de diferentes animais. O cDNA de cada amostra foi pré-amplificado antes de ser usado na análises de expressão relativa, devido à baixa quantidade de material para cada amostra. As células da granulosa pertencentes aos COCs, após sua remoção por ação da enzima hialuronidase, também foram utilizadas para análise da expressão relativa do mRNA para os genes AMH, AMHRII e FSHR. Somente dois pools de células da granulosa foram utilizados por grupo de COCs. O número de células presente em cada pool de células da granulosa não foi estimado.

As análises estatísticas foram realizadas utilizando os dados obtidos para todos os grupos de oócitos provenientes dos COCs graus I, II e III em todas as concentrações de AMH utilizadas $(0,10,50,150$ e $300 \mathrm{ng} / \mathrm{ml})$. Como se pode observar na figura 8 , não houve diferença significativa entre as amostras para os genes AMHRII e FSHR nos oócitos estudados ( $\mathrm{p}=0.12$ e $\mathrm{p}=0.27$, respectivamente). Nossos resultados demonstram que a expressão relativa do mRNA AMHRII nos oócitos foi baixa, porém existente, confirmando que o oócito possui receptores para este hormônio. Assim, pode-se sugerir que o hormônio produzido nas células da granulosa se liga ao seu receptor presente no oócito, resultando em um sinal positivo para o oócito seguir na maturação, conforme proposto por Hayashi e colaboradores (2010). Já a expressão relativa do mRNA FSHR foi muito baixa para a maioria das amostras, sendo na maior parte, não detectada (Figura 8 B).

A.

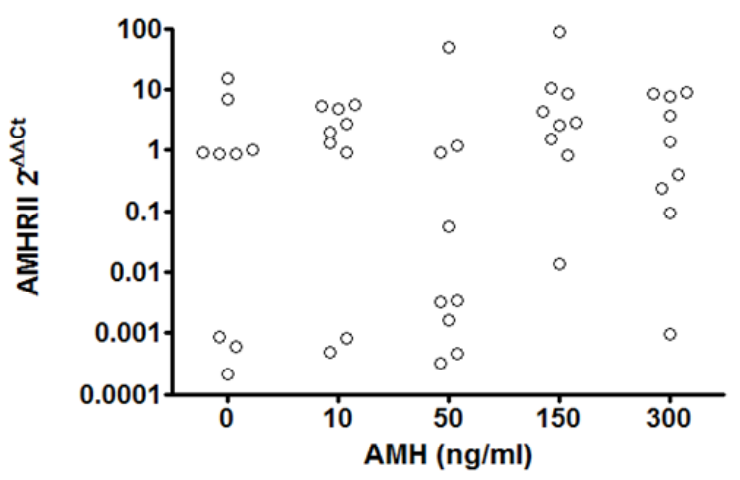

B.

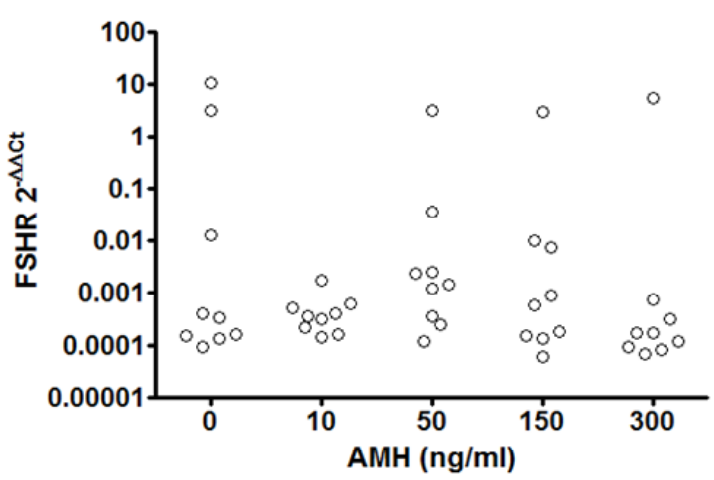

Figura 8. Expressão relativa de mRNA (unidades arbitrárias) de AMHRII (A, p=0.12) e FSHR (B, $\mathrm{p}=0.27$ ) nos oócitos provenientes de COCs graus I, II e III, após maturação em diferentes concentrações de AMH $(0,10,50,150$ e $300 \mathrm{ng} / \mathrm{ml})$. A análise estatística por Kruskal-Wallis demonstrou que não houve diferença significativa na expressão relativa quando os COCs foram maturados na presença do AMH. (*) $\mathrm{p}<0.05$. 
Quando a expressão relativa do mRNA para as células da granulosa foi analisada, não foi encontrada diferença significativa entre as amostras para os genes AMH ( $\mathrm{p}=0.99)$, AMHRII ( $\mathrm{p}=0.49$ ) e FSHR ( $\mathrm{p}=0.50$ ) (Figura 9 A, B e C, respectivamente), porém foi possível observar a expressão do mRNA de todos os genes. Já foi demonstrado que nos estágios mais tardios do desenvolvimento folicular, o AMH atenua o crescimento estimulado pelo FSH em folículos pré-antrais (Durlinger et al. 2002). Dessa maneira, foi proposto que o AMH poderia ter uma função em determinar a sensibilidade ao FSH e consequentemente, ter uma função no recrutamento cíclico e seleção do folículo dominante para a ovulação (Durlinger et al. 2002). Conforme demonstrado por Barrends e colaboradores (1995), o aumento na sensibilidade ao FSH nos folículos com baixa expressão de mRNA AMH permitiria esses folículos pré-antrais serem selecionados para continuar o crescimento e ovulação. Nossos resultados não demonstraram uma diminuição do mRNA FSHR quando na presença de diferentes concentrações de AMH. Assim sugere-se que, se existe uma relação entre a concentração de AMH com a sensibilidade ao FSH, este controle deve ocorrer em estágios anteriores no desenvolvimento folicular, de modo que a adição do AMH ao meio de maturação desses folículos não faça diferença nesta fase do desenvolvimento (folículos antrais).

Ao contrário deste papel proposto por alguns pesquisadores, Hayashi e colaboradores (2010) demonstraram uma maior expressão do mRNA AMH em folículos dominantes, quando comparados aos folículos subordinados, monstrando que este fator de crescimento tem um efeito plausível no desenvolvimento do folículo dominante depois da seleção, assim como no recrutamento. Da mesma maneira, Takahashi e colaboradores (2008) também observaram que os oócitos eram mais propensos a serem fertilizados quando seu folículo era apto a produzir altos níveis de $\mathrm{AMH}$, uma vez que os níveis de $\mathrm{AMH}$ no fluido folicular de oócitos fertilizados eram mais do que três vezes maior do que folículos de oócitos não fertilizados em humanos. Nossos resultados não apresentaram diferença na expressão do mRNA AMHRII e do AMH, mesmo quando adicionado AMH ao meio de maturação. Durlinger e colaboradores (2002), também observaram que mesmo quando adicionados AMH ao meio de cultura de ovários de camundongos, não foi observado nenhum efeito na expressão de mRNA AMHRII. Esses resultados não explicam melhora na porcentagem de embriões obtida após a maturação dos COCs graus II e III em 150ng/ml de AMH, uma vez que não foi observado um aumento na expressão relativa de mRNA do AMHRII, nem do AMH entre os grupos estudados. Assim, supõe-se que esta melhora se deve a outros fatores envolvidos, que não foram estudados neste trabalho. 
Por meio dos dados obtidos, não é possível fazer uma correlação da expressão de nenhum dos genes estudados, uma vez que a adição do hormônio em diferentes concentrações não alterou em nenhuma forma a expressão dos genes estudados. Nielsen e colaboradores (2010), trabalhando com folículos antrais em humanos, também verificaram que não havia correlação entre a expressão de AMH com a de seu receptor, nem com a do FSHR, porém verificaram que a expressão do AMHRII está correlacionada com a do FSHR. Dessa forma, eles concluíram que estes efeitos opostos do AMH/AMHRII ressaltam as vias regulatórias complexas que envolvem a sinalização pelo $\mathrm{AMH}$, e justificam a realização de novos estudos.
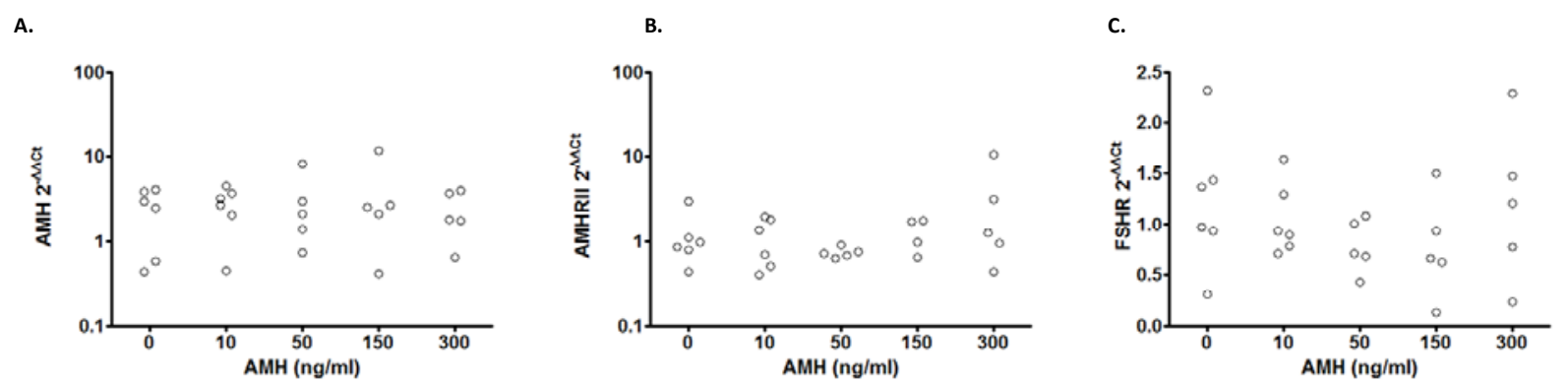

Figura 9. Expressão relativa de mRNA (unidades arbitrárias) de $\mathrm{AMH}(\mathrm{A}, \mathrm{p}=0.99)$, AMHRII (B, $\mathrm{p}=0.49)$ e FSHR $(\mathrm{C}, \mathrm{p}=0.50)$ nas células da granulosa provenientes de COCs graus I, II e III, após maturação em diferentes concentrações de $\operatorname{AMH}(0,10,50,150$ e $300 \mathrm{ng} / \mathrm{ml})$. A análise estatística por Kruskal-Wallis demonstrou que não houve diferença significativa na expressão relativa quando os COCs foram maturados na presença do AMH. $\left({ }^{*}\right) \mathrm{p}<0.05$.

Apesar de não ter sido encontrada diferença significativa entre os grupos estudados, pode-se verificar nas figuras 8 e 9 que existe uma grande variação nos níveis de expressão do mRNA para cada gene, dentro de cada grupo. Essa heterogeneidade de expressão dentro de um mesmo grupo sugere que todos os folículos não são criados igualmente e que a seleção pode depender do tipo de expressão gênica de cada folículo (Rico et al. 2009). 
Conclusóes 


\section{CONCLUSÕES}

Os COCs grau I maturados na presença de 10, 50, 150 e 300ng/ml de AMH apresentam similaridade quanto à fertilidade in vitro, ou seja, não apresentaram diferenças quanto ao desenvolvimento de embriões totais viáveis ao sétimo dia de cultivo in vitro.

Os COCs grau II e III maturados na presença de 10, 50 e 300ng/ml de AMH apresentam similaridade quanto à fertilidade in vitro, não apresentando diferenças quanto ao desenvolvimento de embriões totais viáveis ao sétimo dia de cultivo in vitro.

Os COCs grau II e III maturados na presença de 150ng/ml de AMH apresentaram aumento significativo no número de embriões viáveis quando comparados ao grupo controle.

A expressão relativa dos genes AMHRII e FSHRII em oócitos provenientes de COCs graus I, II e III, maturados na presença de 10, 50, 150 e 300ng/ml de AMH, não apresentou diferença significativa quando comparada à expressão observada no grupo controle.

A expressão relativa dos genes AMHRII, AMH, e FSHRII em células da granulosa provenientes de COCs graus I, II e III, maturados na presença de 10, 50, 150 e 300ng/ml de $\mathrm{AMH}$, não apresentou diferença significativa quando comparada à expressão observada no grupo controle. 
Referências Bibliográficas 


\section{REFERÊNCIAS BIBLIOGRÁFICAS}

BAARENDS WM, UILENBROEK JT, KRAMER P, HOOGERBRUGGE JW, VAN LEEUWEN EC, THEMMEN AP, GROOTEGOED JA. Anti-müllerian hormone and antimüllerian hormone type II receptor Messenger ribonucleic acid expression in rat varies during postnatal development, the estrous cycle, and gonadotropin-induced follicle growth. Endocrinology 1995; 136: 4951-4962.

BETTERIDGE KJ. A history of farm animal embryo transfer and some associated techniques. Anim Reprod Sci, v.79, p.203-244, 2003. Embryo transfer in small ruminant. Norsk Veterinaertidsskr, v.106, p.750-753, 1994.

CARLSSON LB, SCOTT JE, VISSER, JA, RITVOS, O, THEMMEN, APN, HOVATTA, O. Anti:Müllerian hormone inhibits initiation of growth of human primordial ovarian follicles in vitro. Human Reproduction 2006; 21 (9): 2223-7.

CATE RL, MATTALIANO RJ, HESSION C, TIZARD R, FARBER NM, CHEUNG A, NINFA EG, FREY AZ, GASH DJ, CHOW EP. Isolation of the bovine and human genes for Müllerian inhibiting substance and expression of the human gene in animal cells. Cell 1986. Jun 6; 45(5):685-698.

CHANG MC. The maturation of rabbit oocytes in culture and their maturation, activation, fertilization and subsequent development in the fallopian tubes. Journal of Experimental Zoology,1955. V.123, p.379-386.

CHANG CL, WANG TH, HORNG SG, WU HM, WANG HS, SOONG YK. The concentration of inhibin B in follicular fluid: relation to oocyte maturation and embryo development. Hum Reprod 2002; 17: 1724-1728.

DESCHAMPS JC, LUCIA JUNIOR T, CORRÊA MN, MACEDO JR, RHEINGANTZ MGT. Otmização da eficiência do processo de produção animal a partir do uso de biotécnicas reprodutivas. Revista Brasileira de Reprodução Animal 2000. V.24:21-29.

DODE MAN. Avanços na maturação ovocitária em bovinos. Acta Scientiae Veterinariae 2006; 34 (Supl 1): 115-129.

DURLINGER AL, KRAMER P, KARELS B, DE JONG FH, UILENBROEK JT, GROOTEGOED JA, THEMMEN AP. Control of primordial follicle recruitment by antiMüllerian hormone in the mouse ovary.Endocrinology 1999. Dec; 140(12):5789-96. 
DURLINGER AL, GRUIJTERS MJ, KRAMER P, KARELS B, KUMAR TR, MATZUK MM, ROSE UM, DE JONG FH, UILENBROEK JT, GROOTEGOED JA, THEMMEN AP. Anti-Müllerina hormone attenuates the effectes of FSH on follicle development in the mouse ovary. Endocrinology 2001. Nov; 142(11):4891-9.

DURLINGER AL, VISSER JA, THEMMEN AP. Regulation of ovarian function: the role of anti-Müllerian hormone. Reproduction 2002. Nov; 124(5):601-9.

DURLINGER AL, GRUIJTERS MJ, KRAMER P, KARELS B, INGRAHAM HA, NACHTIGAL MW, UILENBROEK JT, GROOTEGOED JA, THEMMEN AP. AntiMüllerian hormone inhibits iitiation of primordial follicle growth in the mouse ovary. Endocrinology 2002. Mar; 143(3): 1076-84.

EDWARDS RG. Maturation in vitro of mouse, sheep, cow, pig, rhesus monkey and human ovarian oocytes. Nature, v.196, p.349-351, 1965.

FAIR T, HULSHOF SC, HYTTEL P, GREVE T, BOLAND M. Nucleus ultrastructure and transcriptional activity of bovine oocytes in preantral and early antral follicles. Mol Reprod Dev 1997; 46: 208-215.

FANCHIN R, MENDEZ LOZANO DH, FRYDMAN N, GOUDEON A, DI CLEMENTE N, FRYDMAN R, et al. Anti-Mülerian hormone concentrations in the follicular fluid of the preovulatory follicle are predictive of the implantation potential of the ensuing embryo obtained by in vitro fertilization. J Clin Endocrinol Metab 2007; 925:1796-802.

GILCHRIST RB, THOMPSON JG. Oocyte maturation: emerging concepts and technologies to improve developmental potential in vitro. Theriogenology 2007; 67:6-15.

GONÇALVES, PBD; BARRETA, MH; SIQUEIRA, LC; ANTONIAZZI, AQ. Produção in vitro de embriões bovinos. Ciência Veterinária nos Trópicos 2008; Suplemento 1; 135-138.

GOTTARDI FP, MINGOTI GZ. Maturação de oócitos bovinos e influência na aquisição da competência para o desenvolvimento do embrião. Rev Bras Reprod Anim 2009; V.33, n.2, p.82-94.

HASHIMOTO S, SAEKI K, NAGAO Y, MINAMI N, YAMADA M, UTSUMI K. Effects of cumulus cell density during in vitro maturation of the developmental competence of bovine oocytes. Theriogenology 1998. 49: 1451-1463. 
HAYASHI KG, USHIZAWA K, HOSOE M, TAKAHASHI T. Differential genome-wide expression profiling of bovine largest and second largest follicles: identification of genes associated with growth of dominant follicles. Reprodutive Biology and Endocrinology 2010; 8: 11 .

HIROBE S, HE WW, GUSTAFSON ML, MACLAUGHLIN DT, DONAHOE PK. Müllerian inhibting substance gene expression in the cycling rat ovary correlates with recruited or graafian follicle selection. Biol Reprod 1994. Jun; 50(6):1238-43.

HYTTEL P, FAIR T, CALLESEN H, GREVE T. Oocyte growth, capacitation and final maturation in cattle. Theriogenology 1997; 47: 23-32.

JOST, A. Recherches sur la differenciation sexuelle de l'embryon de lapin. Arch. Anat. Microsc. Morphol. 1947. 36: 217-315.

JUENGEL, JL; SAWYER, HR; SMITH, PR; QUIRKE, LD; HEATH, DA; LUN, S; WAKEFIELD, SJ; MCNATTY, KP. Origins of follicular cells and ontogeny of steroidogenesis in ovine fetal ovaries. Mol. Cell. Endocrinol. 2002. 191: 1-10.

KEVENAAR ME, MEERASAHIB MF, KRAMER P, VAN DE LANG-BORN BM, DE JONG FH, GROOME NP, THEMMEN AP, VISSER JA. Serum anti-mullerian hormone levels reflect the size of the primordial follicle pool in mice. Endocrinology 2006;147:32283234.

KNIGHT PG, GLISTER C. TGF-beta superfalily members and ovarian follicle development. Reproduction 2006. Aug; 132(2):191-206.

KRISHER, RL, WHEELER, MB. Towards the use of microfluidics for individual embryo culture. Reproduction, Fertility and Development 2010; 22, 32-39.

LE GUIENNE, A. Elevage et insemination. Petit atlas de l'ococyte bovin. p. 24-30, 1998.

LONERGAN P, FAIR T, CORCORAN D, EVANS AC. Effect of culture environment on gene expression and developmental characteristics in IVF-derived embryos. Theriogenology 2006; 65:137-152.

MCGEE EA, HSUEH AJ. Initial and cyclic recruitment of ovarian follicles. Endocr Rev. 2000; Apr. 21(2):200-24. 
MERMILLOD P. La production d'embryons bovins in vitro. Tours: Université François Rabelais, 1998: 33.

MERMILLOD P, DALBIÈS-TRAN R, UZBEKOVA S, THÉLIE A, TRAVERSO J-M, PERREAU C, PAPILLIER P, MONGET P. Factors affecting oocyte quality: who is driving the follicle? Reprod Dom Anim 2008. 43 (Suppl. 2): 393-400.

MONNIAUX D, CLEMENTE N, TOUZÉ JL, BELVILLE C, RICO C, BONTOUX M, PICARD JY, FABRE S. Intrafollicular steroids and anti-müllerian hormone during normal and cystic ovarian follicular development in cow. Biol Reprod 2008. Aug; 79(2):387-96.

NEVES JP, MIRANDA KL, TORTELLA RD. Progresso científico em reprodução na primeira década do século XXI. Revista Brasileira de Zootecnia 2010; V.39: 414-421.

NIELSEN EM, RASMUSSEN IA, FUKUDA M, WESTERGAARD LG, YDING AC. Concentrations of anti-Müllerian hormone i fluid from small human antral follicles show a negative correlation with CYP19 mRA expression in the corresponding granulosa cells. Mol Hum Reprod 2010. Sep; 16(9):637-43.

PARROTT JA, SKINNER MK. Kit ligand on ovarian stromal cells: effects on theca cell recruitment and steroid production. Molecular Reproduction and Development. 2000. 55: $55-64$.

RICO C, FABRE S, MÉDIGUE C, DI CLEMENTE N, CLÉMENT F, BONTOUX M, TOUZÉ JL, DUPONT M, BRIANT E, RÉMY B, BECKERS JF, MONNIAUX D. Antimullerian hormone is an endocrine marker of ovarian gonadotropin-responsive follicles and can help to predict superovulatory responses in the cow. Biol Reprod. 2009 Jan; 80(1):50-9.

ROSENKRANS, C. F., JR. \& FIRST, N. L. Effect of free amino acids and vitamins on cleavage and developmental rate of bovine zygotes in vitro. J Anim Sci 1994 72(2): 434-7.

SKINNER MK, SCHMIDT M, SAVENKOVA MI, SADLER-RIGGLEMAN I, NILSSON EE. Regulation of granulosa and theca cell transcriptomes during ovarian antral follicle development. Mol Reprod Dev 2008. Sep; 75(9):1457-72.

SMITZ, J; CORTVRINDT, R. The earliest stages of folliculogenesis in vtro. Reproduction 2002; 123: 185-202.

STEPTOE, PT; EDWARDS, RG. Birth after reimplantation of human embryo. Lancet 1978, V.2; p.366. 
TAKAHASHI C, FUJITO A, KAZUDA M, SUGIYAMA R, ITO H, ISAKA K. AntiMüllerian hormone substance from follicular fluid is positively associated with success in oocyte fertilization during in vitro fertilization. Fertility and Sterelity 2008; 89:586-591.

TANGHE S, VAN SOOM A, MEHRZAD J, MAES D, DUCHATEAU L, DE KRUIF A. Cumulus contributions during bovine fertilization in vitro. Theriogenology 2003. 60: 135-19.

UENO S, KURODA T, MACLAUGHLIN DT, RAGN RC, MANGANARO TF, DONAHOE PK. Müllerian inhibiting substance in the adult rat ovary during various stages of the estrous cycle. Endocrinology 1989. Aug; 125(2):1060-6.

VAN DN HURK R, ZHAO J. Formation of mammalian oocytes and their growth, differentiation and maturation within ovarian follicles. Theriogenology 2005; Apr $1 ; 63(6): 1717-1751$.

VARAGO FC, MENDONÇA LF, LAGARES MA. Produção in vitro de embriões bovinos: estado da arte e perspectiva de uma técnica em constante evolução. Rev Bras Reprod Anim 2008. V.32: 100-109.

VIANA JHM, CAMARGO LSA, FERREIRA AM, SA WF, FERNANDES CAC, JUNIOR APM. Short intervals between ultrasonographically guided follicle aspiration improve oocyte quality but do not prevent establishment of dominant follicles in the Gir breed (Bos indicus) of cattle. Animal Reproduction Science 2004; 84: 1-12.

VISSER JA, MCLUSKEY A, VERHOEF-POST M, KRAMER P, GROOTEGOED JA, THEMMEN AP. Effect of prenatal exposure to diethylstilbestol on Müllerian duct development in fetal male mice. Endocrinology 1998. Oct; 139(10):4244-4251.

WEENEN C, LAVEN JS, VON BERGH AR, CRANFIELD M, GROOME NP, VISSER JA, KRAMER P, FAUSER BC, THEMMEN AP. Anti-Müllerian hormone expression pattern in the human ovary: potential implications for initial and cyclic follicle recruitment. Mol Hum Reprod. 2004. Feb; 10(2):77-83.

WU B, ZAN L. Enhance beef cattle improvement by embryo biotechnologies. Reprod Domest Anim. 2011 Dec 1. 
Anexo de Publicação 


\section{Anti-Müllerian hormone supplementation improves bovine embryo development in vitro}

Adriana Renzi, Fernanda Prado Elias, Henrique Nunes de Oliveira, Reginaldo Aparecido Vila, Raysildo Barbosa Lôbo.

Departamento de Genética, Faculdade de Medicina de Ribeirão Preto, Universidade de São Paulo, Av. Bandeirantes 3900, Ribeirão Preto, SP 14049-900, Brazil.

Corresponding author: Raysildo Barbosa Lôbo.

Tel: +55-16-3602-4909

Fax: $+55-16-3602-4910$

E-mail: rayblobo@rge.fmrp.usp.br 


\section{ABSTRACT}

The in vitro oocyte maturation (MIV) is an important reproductive technology that generates mature oocytes able to support the preimplantation embryonic development and their fully evolution to term. Many factors lead to oocyte maturation process, and the AMH (Anti-Müllerian hormone) have demonstrated important effects in the oocyte development. Here, we report the influence of AMH supplementation in the cumulus-oocyte complex (COCS) maturation. We found that AMH had no effect on embryo production of COCs grade I. On the other hand, significant differences between the COCs grade II and COCs grade III matured in AMH $150 \mathrm{ng} / \mathrm{ml}$ was verified. Taken together, the results corroborate the important roles for $\mathrm{AMH}$ on embryo production, as well as, suggest that $\mathrm{AMH}$ supplementation could achieve successful outcome in the production of blastocysts. 


\section{INTRODUCTION}

The in vitro oocyte maturation (MIV) is an important reproductive technology that generates mature oocytes able to support the preimplantation embryonic development and their fully evolution to term. In domestic animals the embryo production from non-stimulated ovaries using MIV is a routine practice, being an important technologic platform for artificial reproduction, cloning and production of transgenic animals. While in humans, the infertility treatment with MIV does not have a successful outcome, the improvement of the method would diminish stimulating hormones use, as well as the costs of the procedure (Gilchrist and Thompson, 2007).

Many factors act on the oocyte maturation process (which includes all responsible events to generate maximum development potential after fecundation). This is one of the most important steps, for it is in this period that the oocyte acquires the ability to proceed in the events of embryonic development. During the follicular development final step, the oocyte resides in an antral follicle and a humoral microenvironment is created in the surrounding fluid. Through folliculogenesis, the communication in the cumulus-oocyte complex (COC) becomes more intense, occurring bi-directional elements transfer between the cumulus cells and the oocyte (Dode, 2006). The final step in cytoplasmic and meiotic maturation of the oocyte is object of complex endocrine, paracrine and autocrine interactions. The intrafollicular concentration of some of these agents in specific periods of the antral follicular development appears to be related with the success or failure of various oocyte development processes, which are essential for fertilization and future embryo development (Fanchin et al, 2007). Thus, the progression of capable oocytes in a population of growing follicles might be the result of oocyte differentiation through the accumulation of factors (such as messengers and proteins) which will be involved in the success of development onset or the result from the follicles selection containing suitable oocytes, in a highly selective humoral environment and challenging intrafollicular regulation (Mermillod et a, 2008). Nowadays, the efficiency of MIV technologies is limited by the development of the intrinsic oocyte competence. In spite of its limitations, this is a most valuable technology, since it allows dealing 
with a much different oocyte population, harvested from follicles in many different development stages, dominance and atresia (Gilchrist and Thompson, 2007).

Among the factors which affect oocyte development, it has gained much attention the effects of AMH (Anti-Müllerian hormone), which is a glycoprotein belonging to the family of transforming growthfactors (TGF)- $\beta$, whose expression is only found in gonads (Cate et al. 1986). Beyond the AMH inhibitor role in the recruitment of primordial follicles by neighbor growing follicles which secretes it (Durlinger et al. 1999), one study conducted by Hayashi et al. (2010) found differences in AMH expression when comparing dominant and subordinated follicles pos-recruitment in cattle, being higher in granulosa cells of follicles regarded as dominant, suggesting an association between this hormone and the establishment and maintenance of follicular dominance after its selection. It was also demonstrated by Takahashi et al. (2008), that high AMH levels in the follicular fluid are correlated with oocyte fertilization success after IVF (in vitro fertilization), evidencing that $\mathrm{AMH}$ might have an essential role in oocyte fertilization and development. Although the functional role of $\mathrm{AMH}$ in the development of antral follicles is not well established, recent studies show a high $\mathrm{AMH}$ intrafollicular concentration, and a high mRNA-AMH expression in small antral follicles, decreasing with follicular growth, suggesting also AMH involvement in cattle follicular recruitment and/or selection (Monniaux et al, 2008; Rico et al, 2009).

In view of $\mathrm{AMH}$ importance in follicular development and oocyte selection, and the knowledge of what its action would bring to the assisted reproduction techniques, we investigated whether the $\mathrm{AMH}$ supplementation improves bovine embryo development. We found that $\mathrm{AMH}$ $(150 \mathrm{ng} / \mathrm{ml})$ is able to influence the embryo production in COCs grade II and III.

\section{MATERIAL AND METHODS}

\section{Oocyte recovery and in vitro maturation}

The oocytes were collected from ovaries obtained at a slaughter house and transported to the laboratory (until 2 hours after slaughter) in a thermal recipient containing sterile saline solution with 
penicillin $(100 \mathrm{UI} / \mathrm{mL})$ and streptomycin $(50 \mathrm{mg} / \mathrm{mL})$ at $35^{\circ} \mathrm{C}$. Cumulus-oocyte complexes (COCs) were aspirated from 2-8 mm diameter antral follicles, by manual aspiration using an 18-G needle and a 10 $\mathrm{ml}$ syringe. The COCs were classified and separated by stereomicroscope according to the morphological characteristics. COCs grade 1: complete and compact multilayers of cumulus and homogeneous ooplasm; COCs grade 2: with two or three compact layers of cumulus cells, homogeneous ooplasm; COCs grade 3: less than two layers of cumulus cells, part of the pellucid zone can be exposed, heterogeneous ooplasm.

After the selection, the COCs washed twice in a TCM-199 washing medium with Earle's salts, glutamine, $\mathrm{NaHCO}_{3}, \mathrm{HEPES}$ (Gibco Laboratory, Grandlsland, NY, USA) supplemented with $10 \%$ deactivated bovine fetal serum (SFB, Gibco Laboratory, Grandlsland, NY, USA), sodium pyruvate (0.2 $\mathrm{mM}$ ) and gentamicin sulfate (Sigma Chemical Co., St. Louis, MO, USA). Then, the COCS were washed twice in TCM-199 maturation medium with Earle's salts, glutamine, $\mathrm{NaHCO}_{3}$, with addition of $10 \%$ of deactivated SFB, sodium pyruvate $(22 \mu \mathrm{g} / \mathrm{mL})$, estradiol $(1 \mu \mathrm{g} / \mathrm{mL}), \mathrm{FSH}(0.5 \mu \mathrm{g} / \mathrm{ml})$ and $\mathrm{LH}(50 \mu \mathrm{g} / \mathrm{mL})$. To test the dose response to $\mathrm{AMH}$, we added human recombinant AMH (R\&D Systems - Recombinant Human MIS) to the maturation medium at four different concentrations: $10 \mathrm{ng} / \mathrm{ml}, 50 \mathrm{ng} / \mathrm{ml}$, $150 \mathrm{ng} / \mathrm{ml}$ and $300 \mathrm{ng} / \mathrm{ml}$. The COCs were separated in groups according to their morphological characteristics and placed in drops of maturation medium on $35-\mathrm{mm}$ plates covered with $4 \mathrm{~mL}$ mineral oil in the presence or absence of $\mathrm{AMH}$. Maturation conditions were $5 \%$ of $\mathrm{CO} 2$ in humidified atmosphere, at $39^{\circ} \mathrm{C}$ for 24 hours.

\section{In vitro fertilization}

After 24 hours of in vitro maturation, the COCs were washed twice in fertilization medium (TALP supplemented with heparine- $10 \mu \mathrm{g} / \mathrm{ml}$, pyruvate- $22 \mu \mathrm{g} / \mathrm{ml}$, gentamicine- $50 \mathrm{mg} / \mathrm{ml}$, BSA without fat acids $-6 \mathrm{mg} / \mathrm{ml}$ and PHE solution- $2 \mu \mathrm{M}$ of penicillamine, $1 \mu \mathrm{M}$ of hypotaurine and $0,25 \mu \mathrm{M}$ of epinephrine) and placed on drops of of the same medium on $35-\mathrm{mm}$ plates covered with $4 \mathrm{~mL}$ 
mineral and co-incubated with sperm at the concentration of $2 \times 10^{6}$ spermatozoa/mL for 12 hours, at $39^{\circ} \mathrm{C}, 5 \%$ of $\mathrm{CO}_{2}$ in open air and maximum humidity.

\section{Embryo culture}

After the incubation period, the supposed zygotes were washed and subjected to pipetting in IVF medium to remove the excess of cumulus cells and sperm adhered, so that there only 3 layers of cumulus cells adhered to the pellucid zone, The zygotes were co-cultivated with monolayers of cumulus cells in microdrops of $50 \mu$ l of microdrops of cultivation medium CR2aa (Rosenkrank; First, 1994) with addition of $10 \%$ of SFB and aminoacids, covered with mineral oil for 168 hours after the beginning of in vitro fertilization under incubation in atmosphere with $5 \%$ of $\mathrm{CO}_{2}$ in open air at $39^{\circ} \mathrm{C}$.

On the fourth day of cultivation, the unviable structures were removed, as well as the excess cumulus cells, and the microdrops were refreshed with the removal of $30 \mu \mathrm{l}$ of medium and addition of $30 \mu$ l of new cultivation medium.

\section{Embryo development}

After the incubation period (168 hours after IVF), the number of viable embryos was evaluated, and the embryos were classified according to their morphology into: early blastocyst (starting the cavitation process, with the cavity being less than $50 \%$ of total volume); blastocyst (cavity occupy around $50 \%$ of the total volume); expanded blastocyst (cavity occupy more than $50 \%$ of the total volume, thin pellucid zone) and ecloded blastocyst (blastocyst ecloding or out of the pellucid zone).

\section{Statistical analysis}

Statistical analyses were performed using the FREQ procedure of SAS statistical package (SAS ${ }^{\circ}$, Version 9.2). The chi-square was applied, adopting the significance level of $5 \%$. 


\section{RESULTS AND DISCUSSION}

To evaluate the impact of AMH in the oocyte maturation of three different grade of COCs, the effect of $\mathrm{AMH}$-treatment on the rate of embryo production in vitro was examined. A total of 4949 collected COCs belonging to the three morphological categories (grade I, II and III) were submitted to IVF procedures, after being matured in the presence or absence of $\mathrm{AMH}$ in four different concentrations (10ng/ml, $50 \mathrm{ng} / \mathrm{ml}, 150 \mathrm{ng} / \mathrm{ml}$ e $300 \mathrm{ng} / \mathrm{ml}$ ). AMH had no effect on embryo production of COCs grade I (Table 1 and Figure 1A). On the other hand, significant differences between the COCs grade II (Table 2 and Figure 1B) and COCs grade III (Table 3 and Figure 1C) matured in AMH $150 \mathrm{ng} / \mathrm{ml}$ was detected, when compared with control ( $p<0.0001$ and $p=0.0004$, respectively).

Since the granulosa cells are responsible for the production of various factors that influence the oocyte, including the $\mathrm{AMH}$, when these cells are removed from the COCs, the fertilization rate declines abruptly (Hashimoto et al. 1998; Tanghe et al. 2003). In this way, COCs that have less cumulus cells around the oocyte can be helped with the addition of this hormone to the maturation medium, as corroborated by our results. The concentrations of 10,50 and $300 \mathrm{ng} / \mathrm{ml}$ of $A M H$, had no effect on blastocysts production (Figure $1 \mathrm{~A}, 1 \mathrm{~B}$ and $1 \mathrm{C}$ ). It is possible that higher concentrations of this hormone could down-regulate $\mathrm{AMH}$ receptor and over time render AMH treatment ineffective, as saw by Carlsson et al. (2006), where they found that the addition of $100 \mathrm{ng} / \mathrm{ml}$ of AMH to the culture medium of ovarian tissue suppressed the initiation of growth of primordial follicles, but when used $300 \mathrm{ng} / \mathrm{ml}$, this effect was not observed, showing that $\mathrm{AMH}$ may have a different effect depending on the concentration used. The fact that oocytes derived from COCs grade I did not show significant difference in embryo production after being matured in the presence of $\mathrm{AMH}$, can be explained on the basis of morphological quality of the COCs used. The grade I COCs have more granulosa cells around the oocyte than COCs grade II and III (Viana et al. 2004), so they probably produce enough $\mathrm{AMH}$ to support the oocyte maturation, not being affected by exogenous supplementation. In agreement with our results, Takahashi et al. (2008) have shown the importance 
of $\mathrm{AMH}$ in the development and fertilization of oocytes, as well as its significance in the implantation rate in human (Fanchin et al. 2007).

In conclusion, the results of this study suggest that supplementation of the maturation media with AMH $150 \mathrm{ng} / \mathrm{ml}$ improves the rate of bovine embryo production in vitro when used in COCs of morphological quality grade II and III. The oocyte maturation is a complex process, involving an assembly of factors, whereas AMH is one important hormone correlated, as verified in this study. These results provide evidence that AMH supplementation would help optimize currently used maturation media, enhancing the production of blastocysts. The supplementation of media could help improve the blastocysts rates for cows with low ovulatory response that have lower numbers of recovered oocyte with low quality, as well as could achieve successful outcome in the human infertility treatment.

\section{ACKNOWLEDGEMENTS}

This work was supported by Fundação de Amparo a Pesquisa do Estado de São Paulo (FAPESP). AR was a recipient CNPq Fellowship and this work was part of the Doctoral Thesis.

\section{REFERENCES}

Carlsson LB, Scott JE, Visser, JA, Ritvos, O, Themmen, APN, Hovatta, O. Anti:Müllerian hormone inhibits initiation of growth of human primordial ovarian follicles in vitro. Human Reproduction 2006; 21 (9): 2223-7.

Cate RL, Mattaliano RJ, Hession C, Tizard R, Farber NM, Cheung A, Ninfa EG, Frey AZ, Gash DJ, Chow $E P$, et al. Isolation of the bovine and human genes for Müllerian inhibiting substance and the expression of the human gene in animal cells. Cell 1986. Jun 6; 45 (5): 685-698.

Dode MAN. Avanços na maturação ovocitária em bovinos. Acta Scientiae Veterinariae 2006; 34 (Supl 1): 115-129.

Durlinger AL, Kramer P, Karels B, de Jong FH, Uilenbroek JT, Grootegoed JA, Themmen AP. Control of primordial follicle recruitment by anti-Müllerian hormone in the mouse ovary. Endocrinology, 1999. Dec; 140 (12): 5789-5796. 
Fanchin R, Mendez Lozano DH, Frydman N, Goudeon A, di Clemente N, Frydman R, et al. AntiMülerian hormone concentrations in the follicular fluid of the preovulatory follicle are predictive of the implantation potential of the ensuing embryo obtained by in vitro fertilization. J Clin Endocrinol Metab 2007; 925:1796-802.

Gilchrist RB, Thompson JG. Oocyte maturation: emerging concepts and technologies to improve developmental potential in vitro. Theriogenology 2007; 67:6-15.

Hashimoto S, Saeki K, Nagao Y, Minami N, Yamada M, Utsumi K. Effects of cumulus cell density during in vitro maturation of the developmental competence of bovine oocytes. Theriogenology 1998. 49: 1451-1463.

Hayashi KG, Ushizawa K, Hosoe M, Takahashi T. Differential genome-wide expression profiling of bovine largest and second largest follicles: identification of genes associated with growth of dominant follicles. Reprodutive Biology and Endocrinology 2010; 8: 11.

Le Guienne, A. Elevage et insemination. Petit atlas de l'ococyte bovin. p. 24-30, 1998.

Mermillod P, Dalbiès-Tran R, Uzbekova S, Thélie A, Traverso J-M, Perreau C, Papillier P, Monget P. Factors affecting oocyte quality: who is driving the follicle? Reprod Dom Anim 2008. 43 (Suppl. 2): 393-400.

Rico C, Fabre S, Médigue C, di Clemente N, Clément F, Bontoux M, Touzé JL, Dupont M, Briant E, Rémy $B$, Beckers JF, Monniaux D. Anti-mullerian hormone is an endocrine marker of ovarian gonadotropin-responsive follicles and can help to predict superovulatory responses in the cow. Biol Reprod. 2009 Jan; 80(1):50-9.

Rosenkrans, CF, Jr., First, NL. Effect of free amino acids and vitamins on cleavage and developmental rate of bovine zygotes in vitro. J Anim Sci. 1994; 72(2): 434-7.

Takahashi C, Fujito A, Kazuda M, Sugiyama R, Ito H, Isaka K. Anti-Müllerian hormone substance from follicular fluid is positively associated with success in oocyte fertilization during in vitro fertilization. Fertility and Sterelity 2008; 89:586-591.

Tanghe S, Van Soom A, Mehrzad J, Maes D, Duchateau L, de Kruif A. Cumulus contributions during bovine fertilization in vitro. Theriogenology 2003. 60: 135-19.

Viana JHM, Camargo LSA, Ferreira AM, Sa WF, Fernandes CAC, Junior APM. Short intervals between ultrasonographically guided follicle aspiration improve oocyte quality but do not prevent establishment of dominant follicles in the Gir breed (Bos indicus) of cattle. Animal Reproduction Science 2004; 84: 1-12. 


\section{FIGURES}

Table 1. In vitro embryo production using oocytes from COCs grade $\mathrm{I}$, in different AMH concentration.

\begin{tabular}{lccccc}
\hline \multicolumn{7}{c}{ COCs grade I } & & \\
\hline & GI 0 & GI 10 & GI 50 & GI 150 & GI 300 \\
\hline $\begin{array}{l}\text { Unfertilized } \\
\text { oocytes/unviable } \\
\text { embryos }\end{array}$ & 633 & 184 & 157 & 75 & 132 \\
\hline Viable embryos & $62.43 \%$ & $63.45 \%$ & $60.38 \%$ & $56.39 \%$ & $64.39 \%$ \\
\hline TOTAL & $37.57 \%$ & 106 & 103 & 58 & 73 \\
\hline & 1014 & 290 & 260 & 133 & 205 \\
\hline
\end{tabular}

Table 2. In vitro embryo production using oocytes from COCs grade II, in different AMH concentration.

\begin{tabular}{lccccc}
\hline \multicolumn{6}{c}{ COCs grade II } \\
\hline & GII 0 & GII 10 & GII 50 & $\begin{array}{c}\text { GII 150 } \\
*\end{array}$ & GII 300 \\
\hline $\begin{array}{l}\text { Unfertilized } \\
\text { oocytes/unviable } \\
\text { embryos }\end{array}$ & 536 & 121 & 108 & 68 & 141 \\
\hline Viable embryos & $28.29 \%$ & $61.73 \%$ & $65.06 \%$ & $46.58 \%$ & $64.38 \%$ \\
\hline TOTAL & $34.71 \%$ & $38.27 \%$ & $34.94 \%$ & $53.42 \%$ & $35.62 \%$ \\
\hline
\end{tabular}

Table 3. In vitro embryo production using oocytes from COCs grade III, in different AMH concentration.

\begin{tabular}{lccccc}
\hline \multicolumn{5}{c}{ COCs grade III } \\
\hline & GIII 0 & GIII 10 & GIII 50 & $\begin{array}{c}\text { GIII 150 } \\
*\end{array}$ & $\begin{array}{c}\text { GIII } \\
\mathbf{3 0 0}\end{array}$ \\
\hline $\begin{array}{l}\text { Unfertilized } \\
\text { oocytes/unviable } \\
\text { embryos }\end{array}$ & 565 & 130 & 157 & 60 & 135 \\
\hline $\begin{array}{l}73.09 \% \\
\text { Viable embryos }\end{array}$ & $68.78 \%$ & $67.67 \%$ & $56.60 \%$ & $67.84 \%$ \\
\hline TOTAL & 208 & 59 & 75 & 46 & 64 \\
\hline
\end{tabular}



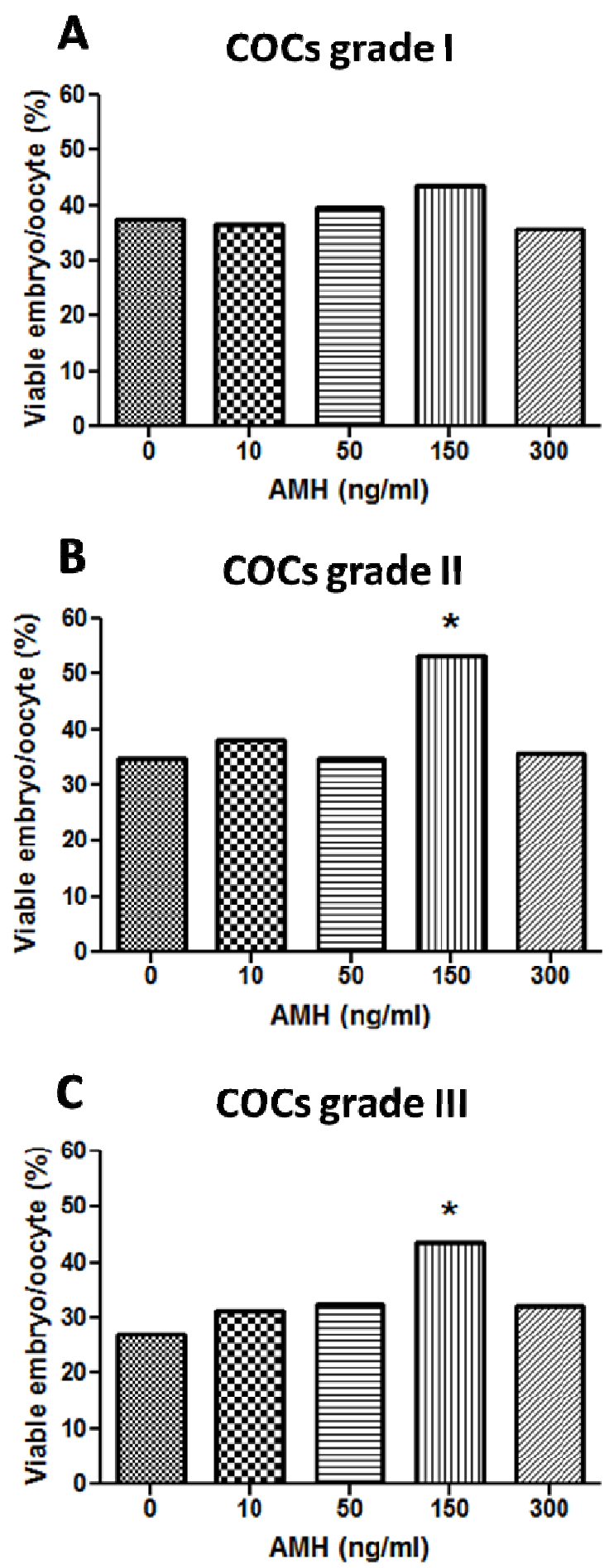

Figure 1. Embryo production rate (number of embryos/number of oocyte) for COCs grade I (A), II (B), III (C), matured in different $\mathrm{AMH}$ concentrations $(0,10,50,150$ and $300 \mathrm{ng} / \mathrm{ml})$. The chi-square analysis showed a significant difference when COCs grade II and III were matured in the presence of AMH 150ng/ml. $\left({ }^{*}\right)$ p $<0.05$. 